\title{
Stability of Slopes Reinforced with Truncated Piles
}

\author{
Shu-Wei Sun, ${ }^{1,2}$ Fu Zhao, ${ }^{1}$ and Kui Zhang ${ }^{1}$ \\ ${ }^{1}$ Faculty of Resources and Safety Engineering, China University of Mining and Technology, Beijing 100083, China \\ ${ }^{2}$ State Key Laboratory of Coal Resources and Safe Mining, China University of Mining and Technology, Beijing, China \\ Correspondence should be addressed to Shu-Wei Sun; ssw1216@163.com
}

Received 10 August 2016; Revised 5 November 2016; Accepted 16 November 2016

Academic Editor: Hossein Moayedi

Copyright (C) 2016 Shu-Wei Sun et al. This is an open access article distributed under the Creative Commons Attribution License, which permits unrestricted use, distribution, and reproduction in any medium, provided the original work is properly cited.

\begin{abstract}
Piles are extensively used as a means of slope stabilization. A novel engineering technique of truncated piles that are unlike traditional piles is introduced in this paper. A simplified numerical method is proposed to analyze the stability of slopes stabilized with truncated piles based on the shear strength reduction method. The influential factors, which include pile diameter, pile spacing, depth of truncation, and existence of a weak layer, are systematically investigated from a practical point of view. The results show that an optimum ratio exists between the depth of truncation and the pile length above a slip surface, below which truncating behavior has no influence on the piled slope stability. This optimum ratio is bigger for slopes stabilized with more flexible piles and piles with larger spacing. Besides, truncated piles are more suitable for slopes with a thin weak layer than homogenous slopes. In practical engineering, the piles could be truncated reasonably while ensuring the reinforcement effect. The truncated part of piles can be filled with the surrounding soil and compacted to reduce costs by using fewer materials.
\end{abstract}

\section{Introduction}

The use of piles for stabilizing active landslides and as a preventive measure in the stable slopes has been considered a reliable and effective technique and has been implemented successfully in a number of applications over the last few decades, for example, [1-7]. A traditional stabilizing pile generally has a full length and pile head extrudes outside the slope surface whose cross section ranges from circular to rectangular [8].

The stabilization of unstable slopes with piles is complicated by factors affecting pile performance under the loading conditions of slope reinforcement and factors controlling the effect of piles on global slope stability. The current design practices for pile-reinforced slopes often use the limit equilibrium methods, where the soil-pile interaction is not considered, and the piles are assumed to only supply an additional sliding resistance. Ito and Matsui [3] have analyzed the development of lateral forces on the stabilizing piles when the soil is forced to squeeze between piles. Ito et al. $[9,10]$ subsequently developed a design method for a pilereinforced slope based on this approach. Poulos [5] presented an approach for evaluating the pressure on single piles where a modified boundary element method is employed to study the response of the passive piles, in which the solution incorporating nonlinear soil-pile interface elements can represent a hardening or softening response prior to reaching an ultimate state. Yamagami et al. [11] reported another limit equilibrium design method for slopes with one row of piles. The method allows two different critical slip surfaces for the two slides of the pile, and the forces acting on the stabilizing piles are estimated based on a given critical slip surface where the safety factor is prescribed to ensure slope stability. Recently, Liang et al. [7] proposed a design procedure for stabilizing an unstable slope with a row of equally spaced drilled shafts, in which the limiting equilibrium-based slope stability analysis method was modified to incorporate the drilled-shaft-induced arching effect through a semiempirical load-transfer factor. In general, the ability of the limit equilibrium methods to determine the stability of slopes reinforced with piles may be in doubt because the soil-pile interaction is not clearly considered.

To better simulate the actual mechanism of failure, numerical methods including the finite element method and the finite difference method have been developed quickly and are becoming increasingly popular for piled slope analysis 


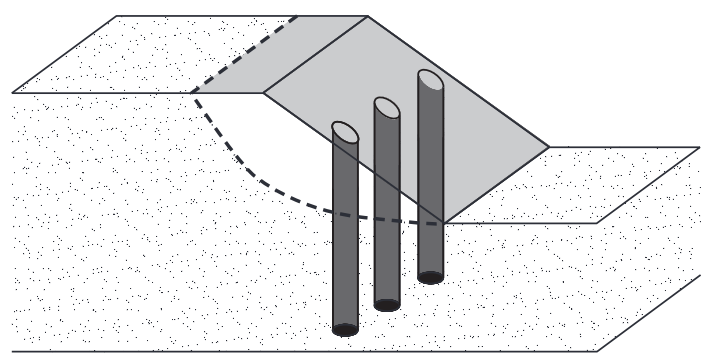

(a) Conventional stabilizing piles (full length)

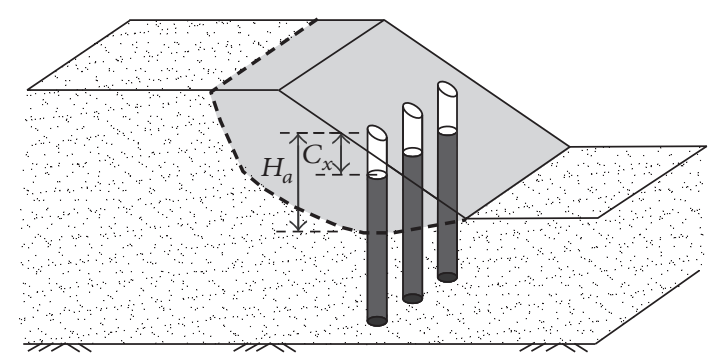

(b) Truncated piles

FIGURE 1: Comparison of conventional stabilizing piles and truncated piles.

based on the shear strength reduction method. Chow [12] presented a numerical model where the piles are modeled using beam elements and the soil is modeled using a hybrid method of elasticity theory analysis. Cai and Ugai [13] have considered the effects of stabilizing piles on the stability of a slope by a three-dimensional (3D) finite element analysis (FEA) using the shear strength reduction method. The effects of pile spacing, pile head conditions, bending stiffness, and pile positions on the safety factor were analyzed and the location of the critical slip surface was determined by the maximum shear force of piles. Wei and Cheng [14] showed that the location of the maximum shear force is not necessarily the location of the critical slip surface for a piled slope, and the critical slip surface for a piled slope is determined by the shear strain rate. One of the main advantages of the shear strength reduction method is that the critical slide surface is found automatically and it is not necessary to specify the shape of the slide surface (e.g., circular, log spiral, and piecewise linear) in advance. Most importantly, numerical methods automatically satisfy translational and rotational equilibrium, and pile behavior characteristics can be obtained simultaneously.

Complicating the issues of pile-stabilized slopes including prediction of load distribution along piles were effects of soil type, pile size and spacing, pile orientation, truncating of piles, and so on $[15,16]$. Most previous research has focused on the response of slopes stabilized with common full length piles as well as the influence factors. However, from the perspective of the rational loading of a pile, if the moment-arm on which the load acts is appropriately shortened while the pile location is unchanged, the sliding thrust acting on the stabilizing pile will be reduced. Therefore, a stabilizing pile with a pile head truncated at a certain depth underneath the slope surface is more economical and rational than a conventional full length pile. To the present author's knowledge, the effect of truncating on the stability of pile-reinforced slopes has never been considered systematically. In this study, the stability of slopes reinforced with truncated piles is analyzed systematically. A simplified numerical method is proposed to analyze the stability of slopes stabilized with truncated piles based on the shear strength reduction method. Besides, the influential factors including pile diameter, pile spacing, depth of truncation, and existence of a weak layer are also systematically investigated from a practical point of view.

\section{Problem Definition and Methodology}

2.1. Problem Definition. The problem definition is given in Figure 1. It can be seen from Figure 1(a) that a conventional stabilizing pile generally has a full length and pile head extrudes outside the slope surface. For truncated piles (see Figure 1(b)), the pile heads are truncated at a certain depth below the surface of a slope, which is unlike traditional stabilizing piles. The key to slope stabilization using piles is the control of the sliding mass. Therefore, once the deformation of the slip surface is suitably restricted, the deformation of the sliding mass that lies on and moves along the slip surface may be restricted to a great extent. A truncated stabilizing pile is proposed for this purpose. The deformation of the sliding mass around the pile head is partially restricted, allowing the load of the sliding mass above the pile head to be released to a certain degree. Thus, the corresponding sliding force is not acting entirely on the piles, and it is possible to reduce the load on the piles. Furthermore, the truncated stabilizing pile has a reduced cost due to its shortened length and smaller load.

The depth of truncation is given by $C_{x}$ and the depth of the critical slip surface is signified by $H_{a}$ in Figure 1(b). To maximize the benefits of the truncated piles, the depth of truncation $C_{x}$ is a key parameter. If $C_{x}$ is too small, the rational capacity of piles cannot be fully achieved; if it is too large, the overpass sliding might occur over pile head and thereby decrease the stability of the reinforced slope. In the interest of generality, the depth of truncation will be expressed in dimensionless form $C$, where $C=C_{x} / H_{a}$.

2.2. Model of Materials. In this study, the soil material of the slope is simulated with an elastic, perfectly plastic model. The yielding is described by a composite Mohr-Coulomb criterion with a tension cutoff as shown in Figure 2 [17].

The failure envelope from points $A$ to $B$ is defined by the Mohr-Coulomb criterion $f^{s}=0$ with

$$
f^{\mathcal{s}}=\sigma_{1}-\sigma_{3} N_{\varphi}+2 c \sqrt{N_{\varphi}}
$$




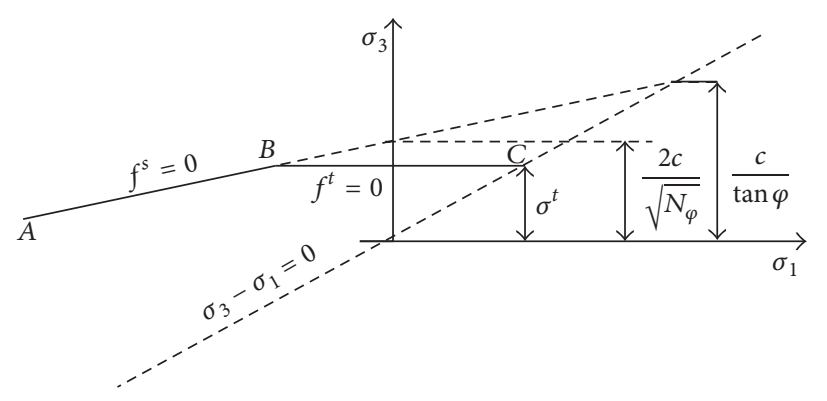

FIgure 2: Composite Mohr-Coulomb failure criterion.

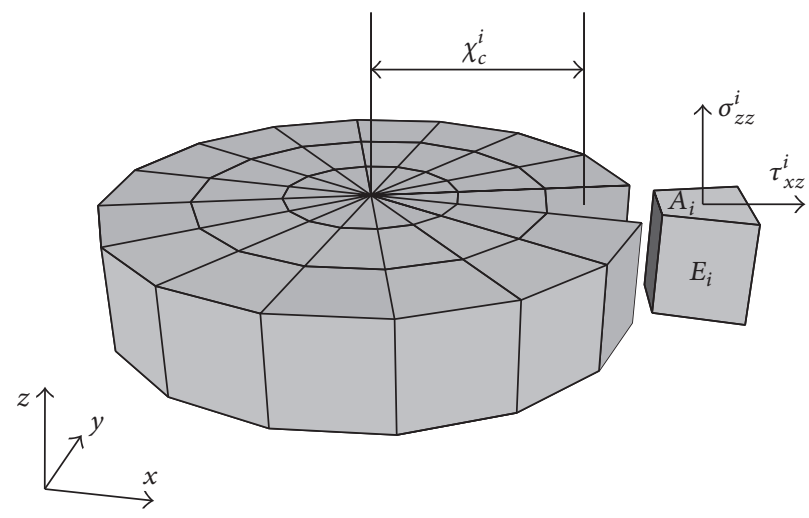

FIGURE 3: Section of a horizontal pile representing parameters in an element.

where $\sigma_{1}$ and $\sigma_{3}$ are the major and minor principal effective stresses, respectively; $c$ is the effective cohesion of soil; $\varphi$ is the internal friction angle of soil; and $N_{\varphi}$ is a function of $\varphi$

$$
N_{\varphi}=\frac{1+\sin \varphi}{1-\sin \varphi}
$$

The failure envelope from points $B$ to $C$ is represented by the tension failure criterion of the form $f^{t}=0$ with

$$
f^{t}=\sigma_{3}-\sigma^{t}
$$

where $\sigma^{t}$ is the effective tensile strength, the maximum value of which, $\sigma_{\max }^{t}$, is given by

$$
\sigma_{\max }^{t}=\frac{c}{\tan \varphi} .
$$

The truncated stabilizing piles are treated as a linear elastic solid material. Routines are developed to calculate the required parameters including the pile shear force and bending moment for the analyses. The shear force $Q$ in each horizontal pile section (see Figure 3) was calculated by multiplying the $x$-direction horizontal shear stress of each element by its plan surface area. The plan area of each element was calculated by dividing its volume by its thickness in the $z$-direction. The bending moment $M$ developed in each pile section was obtained by summation of the product of the vertical stress at each element, the plan area of that element, and the $x$-distance from the center of the pile to the centroid of the element.
The shear force $Q$ and bending moment $M$ are therefore given by

$$
\begin{aligned}
& Q=\sum_{i=1}^{n}\left(\tau_{x z}^{i} \times A_{i}\right) \\
& M=\sum_{i=1}^{n}\left(\sigma_{z z}^{i} \times A_{i} \times x_{c}^{i}\right),
\end{aligned}
$$

where $\tau_{x z}^{i}$ and $\sigma_{z z}^{i}$ are the horizontal shear stress and vertical normal stress of element $E_{i}$ in Figure 3, respectively; $A_{i}$ is the plan area of the element; $x_{c}^{i}$ is the centroid distance of the element from the center of the pile in the $x$-direction; and $n$ is the total number of elements in a horizontal pile section.

2.3. Simulation of Pile-Soil Interface. In this study, the interfaces between piles and soils are characterized by a linear Coulomb shear strength model. Interfaces have the properties of friction, cohesion, dilation, normal and shear stiffness, and tensile and shear bond strength. Figure 4 illustrates the components of the constitutive model acting at an interface node $(P)$.

The normal and shear forces that describe the elastic interface response are determined by the following equations:

$$
\begin{aligned}
& F_{n}{ }^{(t+\Delta t)}=k_{n} u_{n} A+\sigma_{n} A \\
& F_{s i}{ }^{(t+\Delta t)}=F_{s i}{ }^{(t)}+k_{n} \Delta u_{s i}{ }^{(t+(1 / 2) \Delta t)} A+\sigma_{s i} A,
\end{aligned}
$$




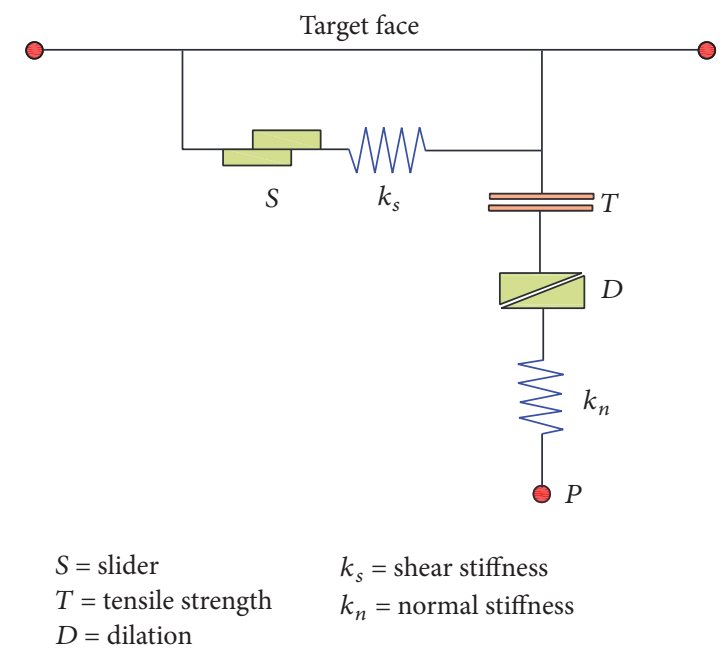

FIGURE 4: Components of the interface constitutive model.

where $F_{n}{ }^{(t+\Delta t)}$ and $F_{s i}{ }^{(t+\Delta t)}$ are the normal and shear force at time $(t+\Delta t)$, respectively; $u_{n}$ is the absolute normal penetration of the interface node into target face; $\Delta u_{s i}$ is the incremental relative shear displacement vector; $k_{n}$ and $k_{s}$ are the normal and shear stiffness, respectively; $\sigma_{n}$ is the additional normal stress added due to interface stress initialization; $\sigma_{s i}$ is the additional shear stress vector due to interface stress initialization; and $A$ is the representative area associated with an interface node.

In this study, where the use of interface element covers the pile-soil separation and nonlinear analysis is carried out, the value for the interface stiffness should be high enough to minimize the contribution of those elements to the accumulated displacements. A good rule-of-thumb is that $k_{n}$ and $k_{s}$ be set to at least ten times the equivalent stiffness of the stiffest neighboring zone [18]. To satisfy this requirement, $k_{n}$ and $k_{s}$ for the interface elements are both taken equal to $1 \times 10^{7} \mathrm{kPa} / \mathrm{m}$ in the current analyses. These values were also adopted by Comodromos and Papadopoulo [19] in their benchmark test on interface elements, which were validated to represent a rough pile interface.

2.4. Determination of the Factor of Safety (FS). For slopes, FS is often defined as the ratio of the actual shear strength to the minimum shear strength required to prevent failure. The conventional way to compute the FS with a finite element or finite difference program is to reduce the shear strength until collapse occurs; FS is the ratio of the soil's actual strength to the reduced shear strength at failure. This shear strength reduction method was used first by Zienkiewicz et al. [20] to compute the FS of a slope composed of multiple materials.

The shear strength reduction method has two main advantages over limit equilibrium slope stability analyses. First, the critical slide surface is found automatically, and it is not necessary to specify the shape of the slide surface in advance. In general, the failure surface geometry for slopes is more complex than simple circles or segmented surfaces. Second, numerical methods automatically satisfy translational and rotational equilibrium, whereas not all limit equilibrium methods do satisfy equilibrium. Consequently, the shear strength reduction method usually determines the FS equal to or slightly less than limit equilibrium methods.

To perform a slope stability analysis with the shear strength reduction method, simulations are run for a series of strength reduction factors $F^{\text {trial }}$ with shear strength parameters $c^{\text {trial }}$ and $\varphi^{\text {trial }}$ adjusted according to the equations:

$$
\begin{aligned}
c^{\text {trial }} & =\frac{1}{F^{\text {trial }}} c \\
\varphi^{\text {trial }} & =\arctan \frac{1}{F^{\text {trial }}} \varphi,
\end{aligned}
$$

where $c$ (cohesion) and $\varphi$ (friction angle) are real shear strength parameters and $F^{\text {trial }}$ is a strength reduction factor.

Figure 5 shows the proposed numerical method to calculate the FS of slopes reinforced with truncated piles. The tensile strength of soil, $T$, in Figure 5 could be set to zero generally. The value of $F^{\text {trial }}$ at which collapse occurs can be found efficiently using bracketing and bisection. First, the value of $F^{\text {trial }}$ is set to be 1.0 initially in order to judge the stability of the piled slope. Then, upper and lower brackets are established. For an initial stable piled slope, the initial lower bracket is any value of $F^{\text {trial }}$ for which a simulation converges, and the initial upper bracket is any value of $F^{\text {trial }}$ for which the simulation does not converge. Conversely, for an unstable piled slope, the initial upper bracket is any value of $F^{\text {trial }}$ for which a simulation converges and the initial lower bracket is any value of $F^{\text {trial }}$ for which the simulation does not converge. Next, a point midway between the upper and lower brackets is tested. For an initial stable slope, the lower bracket is replaced by this new value if the simulation converges, and the upper bracket is replaced if the simulation does not converge. Conversely, for an unstable piled slope, the upper bracket is replaced if the simulation converges, and the lower bracket is replaced if the simulation does not converge. The 


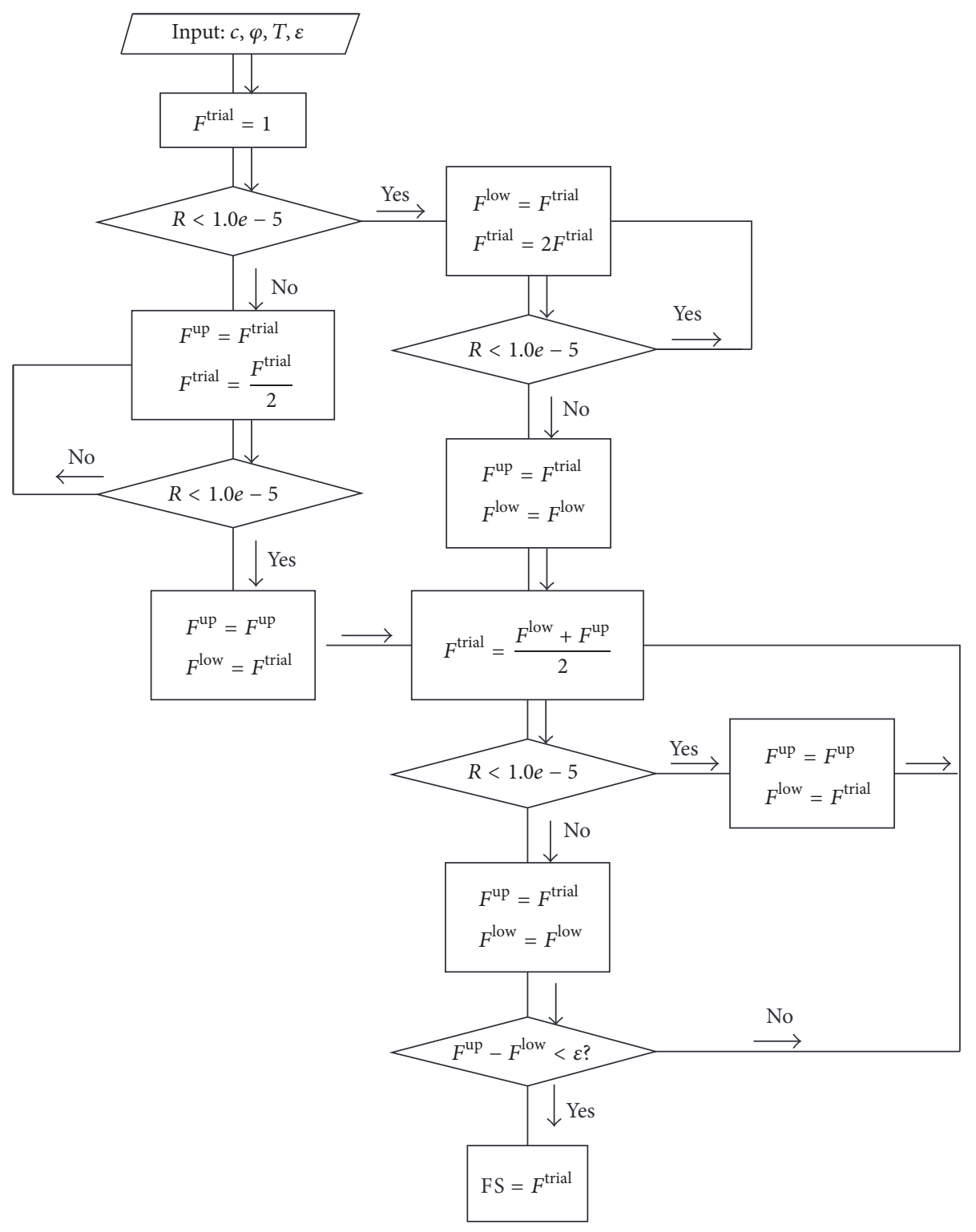

FIGURE 5: Numerical method for obtaining the FS of a truncated piled slope.

process is repeated until the difference between the upper and lower brackets is less than a specified tolerance $\varepsilon$. When this critical value has been found, the factor of safety of the slope is equal to the strength reduction factor and $\mathrm{FS}=F^{\text {trial }}$.

It should be noted that there are several possible definitions of failure, for example, some test of bulging of the slope profile, limiting of the shear stresses on the potential failure surface, or nonconvergence of the solution [21]. In the present analysis, the nonconvergence option is taken as being a suitable indicator of failure. The model is normally assumed to be in equilibrium when the maximum unbalanced force ratio $R$ is below $1 \times 10^{-5}$.

2.5. Method of Execution. The proposed numerical method is executed with FLAC $^{3 \mathrm{D}}$ [22], which is appropriate to simulate the behavior of geomaterials that may undergo plastic flow.
In $\mathrm{FLAC}^{3 \mathrm{D}}$, the explicit calculation scheme and the mixeddiscretization zoning technique facilitate accurate modeling of plastic collapse and flow; and the explicit solution scheme involving a large number of calculation steps progressively redistributes the unbalanced force resulting from changes of the stresses or boundary displacements through the mesh.

The model is considered to be in equilibrium when the maximum unbalanced force for the whole grid is small in comparison with the total of the applied forces associated with boundary displacement or stress changes. Denoting $R$ as the ratio of maximum unbalanced force to the representative internal force, expressed as a percentage, a value of $1 \%$ or $0.1 \%$ may be acceptable as denoting equilibrium, depending on the degree of precision required. If the unbalanced forces approach a constant nonzero value, this usually indicates that failure and plastic flow are occurring within the model. 


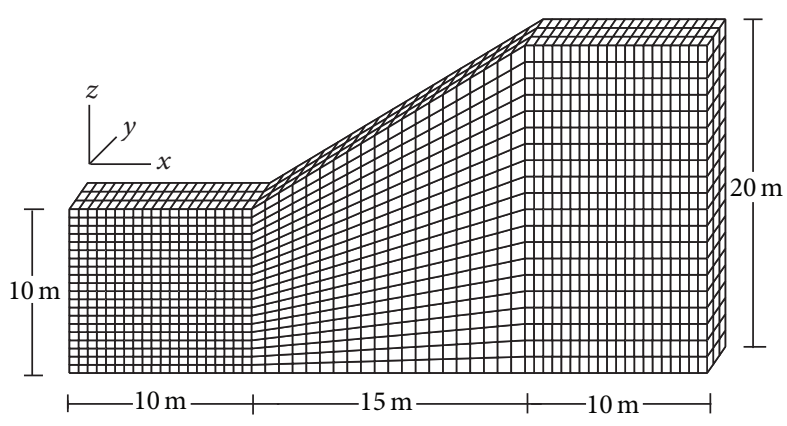

(a) Model A (a homogenous slope)

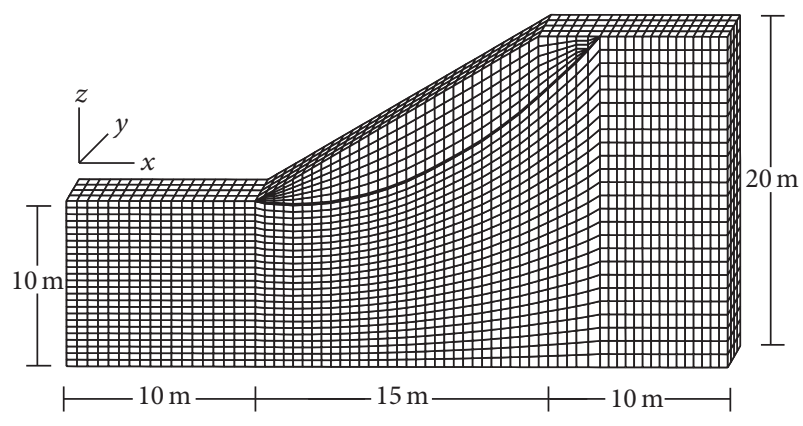

(b) Model B (with a thin weak intercalation)

Figure 6: 3D finite difference mesh for Models A and B.

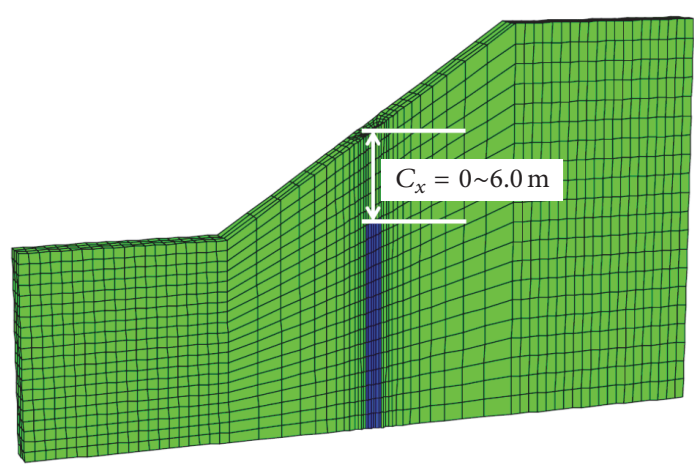

(a) Model A

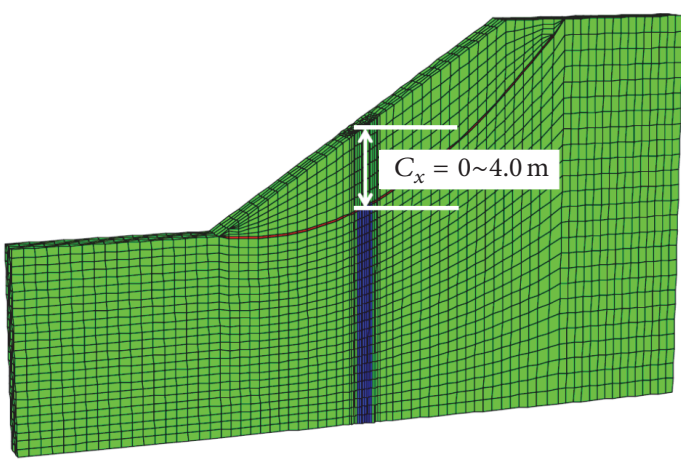

(b) Model B

FIGURE 7: Schematic illustration of the analytical truncated piles.

\section{Validation of the Proposed Method}

3.1. Model Slope. Idealized slopes with a height of $10 \mathrm{~m}$, gradient of $1 \mathrm{~V}: 1.5 \mathrm{H}$, and ground thickness of $10 \mathrm{~m}$ are analyzed using a 3D finite difference mesh, as shown in Figures 6(a) and 6(b). Model A is a homogenous soil slope while Model B has a thin weak intercalation to simulate the effect of a thin weak layer. Both models have the same physical dimensions. The boundary conditions are given as "smoothsmooth" for the 3D analysis [23]. Thus, the bottom $(z=0)$ of slopes is fully fixed, while the left $(x=0)$ and right side $(x=35)$ of the slope are constrained by vertical rollers, and the front $(y=0)$ and far side $(y=S / 2 ; S$ is the pile spacing as stated later) also are constrained by vertical rollers.

Truncated stabilizing piles with outer diameters $D=$ $0.4 \mathrm{~m}, 0.8 \mathrm{~m}$, and $1.6 \mathrm{~m}$ are investigated parametrically in the present study. Piles are installed in the middle of the slope with a distance of slope toe $7.5 \mathrm{~m}$ as shown in Figure 7. The depth of truncation $C_{x}$ in the analysis varies in the range 0$6.0 \mathrm{~m}$ and 0-4.0 $\mathrm{m}$ for Models $\mathbf{A}$ and $\mathbf{B}$, respectively; thus the relative depth of truncation of $C$ ranges approximately from 0 to 1 for both slopes. The pile spacing, $S$, varies from $2 D$ to $8 D$. Two symmetric boundaries are used so that the problem to be analyzed really consists of a row of truncated piles with planes of symmetry through the pile center line and through the soil midway between the piles. Pile heads are free while bottoms are fixed.
TABLE 1: Material properties.

\begin{tabular}{lccc}
\hline Material properties & Pile & Soil & Weak layer \\
\hline Unit weight $\left(\mathrm{kN} / \mathrm{m}^{3}\right)$ & 25 & 20 & 20 \\
Cohesion $(\mathrm{kPa})$ & - & 10 & 7 \\
Friction angle $\left({ }^{\circ}\right)$ & - & 20 & 14 \\
Young's modulus $(\mathrm{MPa})$ & 60,000 & 200 & 100 \\
Poisson's ratio & 0.2 & 0.25 & 0.25 \\
\hline
\end{tabular}

3.2. Validation of the Proposed Numerical Method. It is well documented that the FS of slopes assuming elastic-perfectly plastic constitutive models are insensitive to the construction sequence. In the current study, model slopes in Figure 6 are equilibrated under gravity initially. The purpose of this analysis is to calibrate the numerical model to present the in situ soil conditions. Then, the simulations are run to obtain the FS of slopes following the proposed method. The Mohr-Coulomb model is used to simulate the nonlinear soil behavior as stated above. The Mohr-Coulomb model requires soil parameters including the unit weight, friction angle, cohesion, Young's modulus, and Poisson's ratio. Truncated piles are modeled as a linear elastic material described by parameters of Young's modulus and Poisson's ratio. Material properties in the current analysis are presented in Table 1. 
TABLE 2: FS values of piled slopes for Model A.

\begin{tabular}{|c|c|c|c|c|c|c|c|c|}
\hline \multirow{2}{*}{\multicolumn{2}{|c|}{ Pile spacing }} & \multicolumn{7}{|c|}{$C$} \\
\hline & & 0 & 0.18 & 0.35 & 0.53 & 0.71 & 0.88 & 1.06 \\
\hline \multirow{7}{*}{$D=1.6 \mathrm{~m}$} & $S=2 D$ & 1.78 & 1.69 & 1.51 & 1.33 & 1.22 & 1.18 & 1.17 \\
\hline & $S=3 D$ & 1.64 & 1.61 & 1.47 & 1.32 & 1.21 & 1.17 & 1.17 \\
\hline & $S=4 D$ & 1.57 & 1.54 & 1.44 & 1.32 & 1.21 & 1.17 & 1.17 \\
\hline & $S=5 D$ & 1.53 & 1.50 & 1.42 & 1.31 & 1.21 & 1.17 & 1.17 \\
\hline & $S=6 D$ & 1.49 & 1.47 & 1.41 & 1.31 & 1.21 & 1.17 & 1.17 \\
\hline & $S=7 D$ & 1.47 & 1.45 & 1.40 & 1.30 & 1.21 & 1.17 & 1.17 \\
\hline & $S=8 D$ & 1.44 & 1.44 & 1.38 & 1.30 & 1.21 & 1.17 & 1.17 \\
\hline \multirow{7}{*}{$D=0.8 \mathrm{~m}$} & $S=2 D$ & 1.53 & 1.53 & 1.50 & 1.32 & 1.21 & 1.17 & 1.17 \\
\hline & $S=3 D$ & 1.45 & 1.45 & 1.45 & 1.31 & 1.21 & 1.18 & 1.17 \\
\hline & $S=4 D$ & 1.41 & 1.41 & 1.41 & 1.31 & 1.22 & 1.18 & 1.17 \\
\hline & $S=5 D$ & 1.38 & 1.38 & 1.38 & 1.31 & 1.22 & 1.18 & 1.17 \\
\hline & $S=6 D$ & 1.36 & 1.36 & 1.36 & 1.31 & 1.21 & 1.18 & 1.17 \\
\hline & $S=7 D$ & 1.34 & 1.34 & 1.34 & 1.31 & 1.21 & 1.18 & 1.17 \\
\hline & $S=8 D$ & 1.33 & 1.33 & 1.33 & 1.31 & 1.21 & 1.18 & 1.17 \\
\hline \multirow{7}{*}{$D=0.4 \mathrm{~m}$} & $S=2 D$ & 1.38 & 1.38 & 1.38 & 1.32 & 1.21 & 1.18 & 1.17 \\
\hline & $S=3 D$ & 1.33 & 1.33 & 1.33 & 1.31 & 1.21 & 1.17 & 1.17 \\
\hline & $S=4 D$ & 1.31 & 1.31 & 1.31 & 1.30 & 1.21 & 1.17 & 1.17 \\
\hline & $S=5 D$ & 1.29 & 1.29 & 1.29 & 1.29 & 1.21 & 1.17 & 1.17 \\
\hline & $S=6 D$ & 1.28 & 1.28 & 1.28 & 1.28 & 1.21 & 1.17 & 1.17 \\
\hline & $S=7 D$ & 1.27 & 1.27 & 1.27 & 1.27 & 1.21 & 1.18 & 1.17 \\
\hline & $S=8 D$ & 1.26 & 1.26 & 1.26 & 1.26 & 1.21 & 1.18 & 1.17 \\
\hline
\end{tabular}

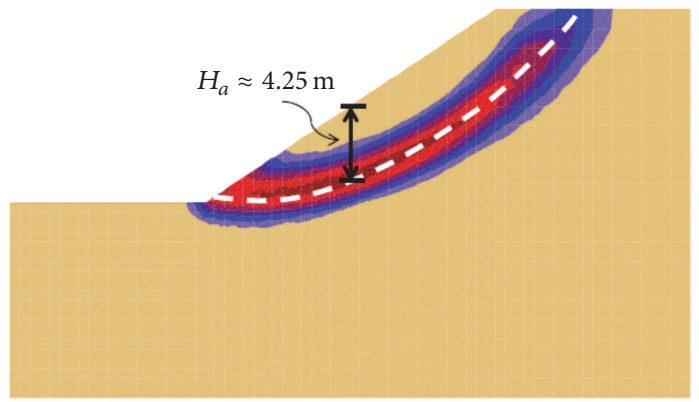

(a) Model A (FS = 1.17)

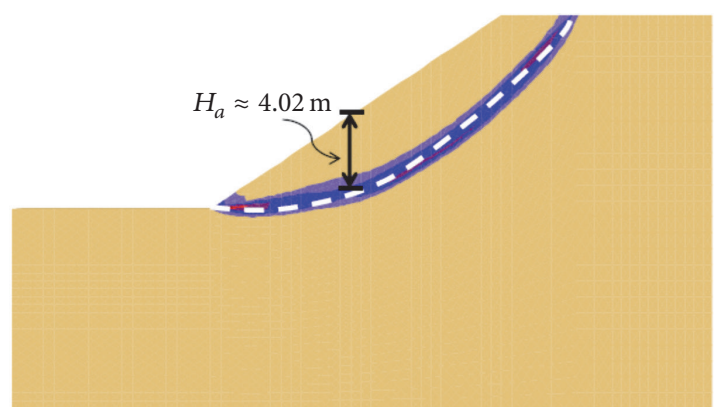

(b) Model B (FS = 0.82)

Figure 8: Critical slip surface of unreinforced slopes for Models A and B.

When the slopes are not reinforced with truncated piles, the FS values for Models A and $\mathbf{B}$ are 1.17 and 0.82, respectively. Compared with the result of 1.14 obtained by Cai and Ugai [13] using the shear strength reduction finite element method for the same slope as Model A, the proposed method shows a slightly higher value for the predicted FS. This is because the FS calculated by FLAC ${ }^{3 \mathrm{D}}$ depends strongly on the size of the element, unlike finite element methods in which a shape function can be used within the elements. In general, the finer element sizes give more precise results. As a check on the result, we performed a 3D Spencer's analysis for Model A and obtained an FS of 1.18. It is demonstrated that the calculated FS values by the proposed method are acceptable.

The critical slip surfaces for the two models are shown in Figure 8, and it can be seen that slope failures occur along a circular surface, which is similar to the results of Cai and Ugai [13]. The depth of the critical slip surface is about 4.25 and $4.02 \mathrm{~m}$ for Models $\mathbf{A}$ and $\mathbf{B}$, respectively.

\section{Results and Discussion}

4.1. Stability of Slopes Reinforced with Truncated Piles. The FS of slopes with piles $D=0.4 \mathrm{~m}, 0.8 \mathrm{~m}$, and $1.6 \mathrm{~m}$ and $S=2 D$ to $8 D$ for Model $\mathbf{A}$ is listed in Table 2. It can be seen that the FS values mainly decrease as $C$ increases. This is because the reinforcement function is gradually lost due to the piles being continuous truncated. When $C$ is up to or above 1 , the FS is 1.17 , which is the same as an unreinforced slope.

The FS of piled slopes for increasing relative truncation length, $C$, shown in Table 2 for Model A are portrayed 


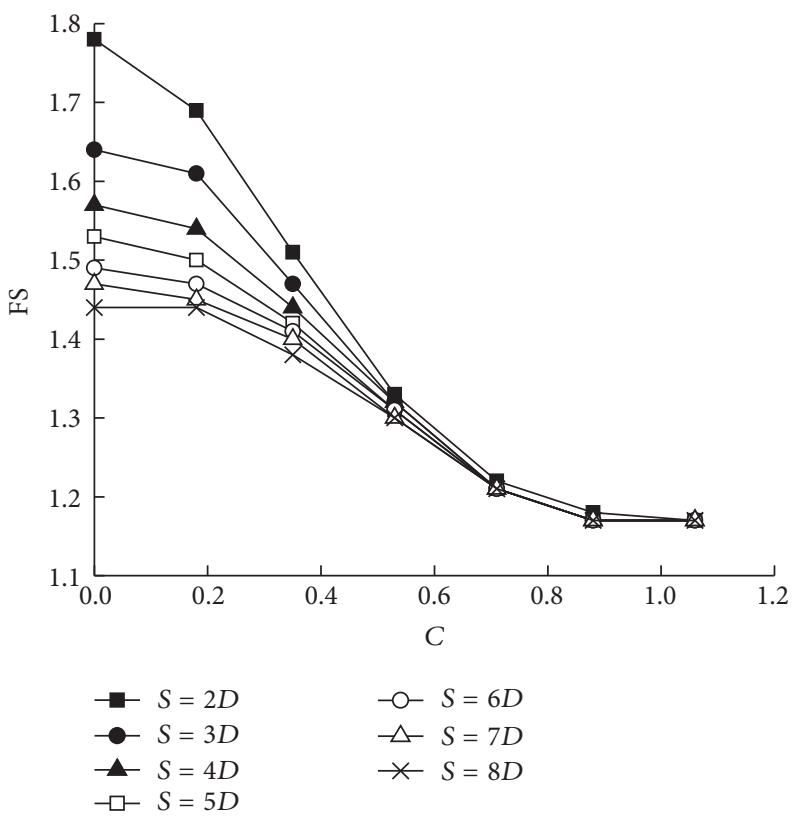

(a) $D=1.6 \mathrm{~m}$

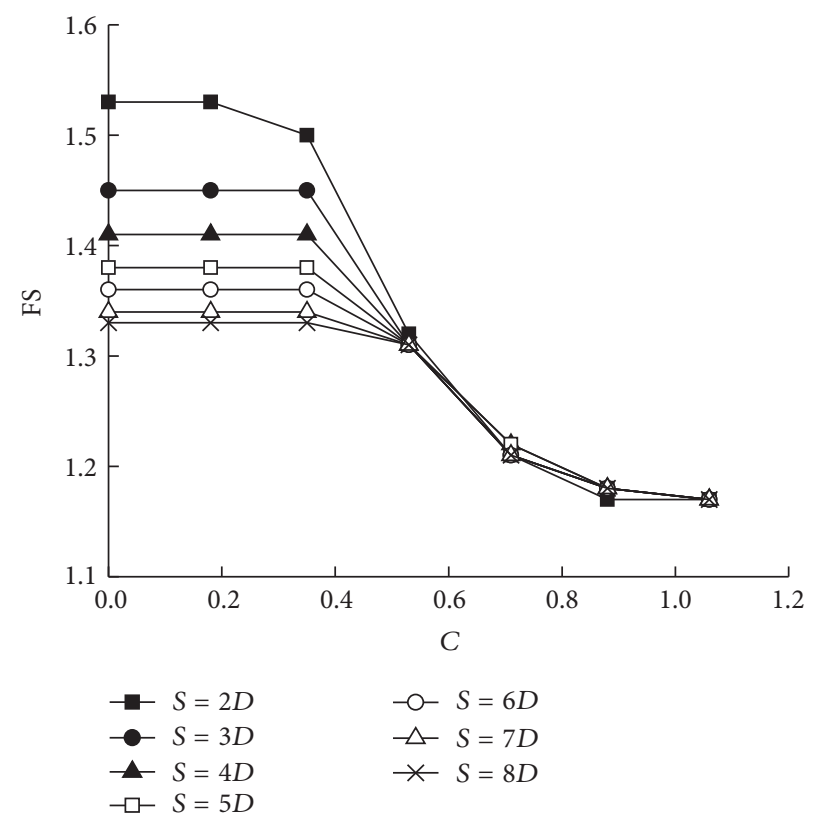

(b) $D=0.8 \mathrm{~m}$

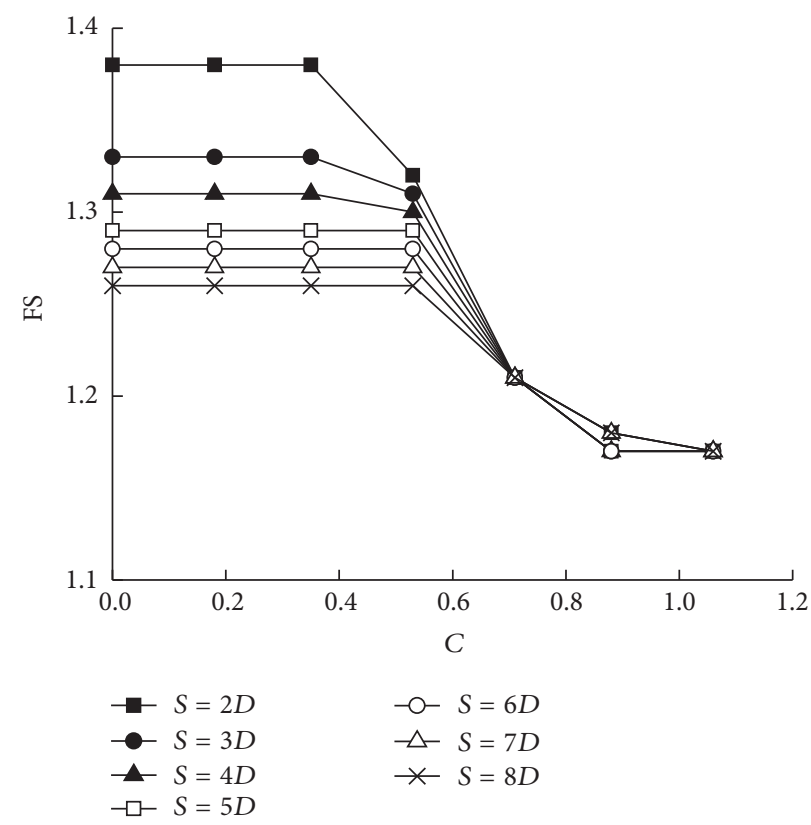

(c) $D=0.4 \mathrm{~m}$

FIGURE 9: FS values of the piled slopes for Model A.

in Figure 9. For $D=1.6 \mathrm{~m}$, it can be seen in Figure 9(a) that FS decreases rapidly with the increasing of $C$ when $S=2 D$. However, when $S$ increases from $3 D$ to $7 D$, FS decrease moderately with $C$ increasing; furthermore, the rate of decline in the FS decreases gradually with $S$ increasing. For $S=8 D$, FS of piled slope remains unchangeable as $C$ increases from 0 to 0.18 and then decreases slowly with the increasing of $C$. For piles with $D=0.8 \mathrm{~m}$ which are more flexible, and when $S=2 D$, it can be seen from Figure 9(b) that value of FS of piled slope remains unchangeable as $C$ increases from 0 to 0.18 , then decreases slightly as $C$ increases from 0.18 to
0.35 , and then decreases rapidly as $C$ is above 0.35 . For $S=3 D$ to $8 D$, FS of piled slopes remain unchangeable as $C$ increases from 0 to 0.18 and then decrease gradually with $C$ increasing. It is also noted that the rate of decline in FS slows down as pile spacing $S$ increases. In Figure $9(\mathrm{c})$, piles with $D=0.4 \mathrm{~m}$ are much more flexible, and when $S=2 D$, it can be seen that FS of piled slopes remains unchangeable as $C$ increases from 0 to 0.35 and then decreases rapidly with $C$ increasing. For $S$ $=3 D$ to $4 D$, the FS of piled slopes remain unchangeable as $C$ increases from 0 to 0.35 , then decrease slightly as $C$ increases from 0.35 to 0.53 , and then decrease rapidly as $C$ is above 0.53 . 


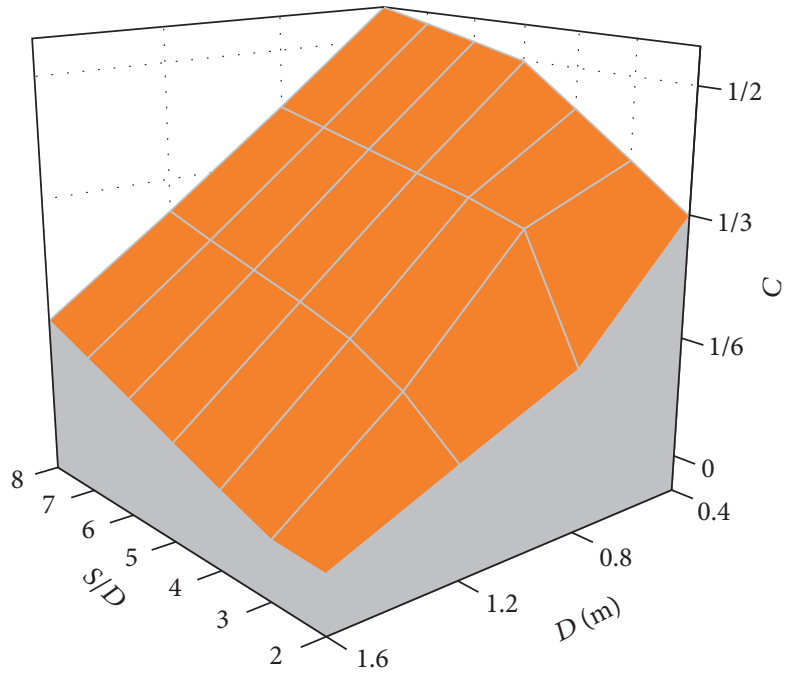

Figure 10: Variation of the $C_{\text {opt }}$ with pile diameter and spacing for Model A.

For $S=5 D$ to $8 D$, FS of piled slopes remain unchangeable as $C$ increases from 0 to 0.53 and then decrease rapidly as $C$ increases above 0.53 .

It can be seen from Figure 19 that an optimum value of the relative depth of truncation, $C$, exists for piles in Model A slopes. The largest truncation length of pile, beyond which overhead sliding may occur, is very meaningful and important for the detailed design of a pile-reinforced slope. The optimal truncation length of pile, beyond which overhead sliding may occur, is investigated with a dimensionless ratio of $C_{\text {opt }}$ as follows:

(1) For $D=1.6 \mathrm{~m}$, the value of $C_{\text {opt }}$ can be taken as $1 / 6$ when $S=8 D$, and values could be zero when $S=2 D$ to $7 D$.

(2) For $D=0.8 \mathrm{~m}$, the value of $C_{\text {opt }}$ can be taken as $1 / 6$ when $S=2 D$ and $1 / 3$ when $S=3 D$ to $8 D$.

(3) For $D=0.4 \mathrm{~m}$, the value of $C_{\text {opt }}$ can be taken as $1 / 3$ when $S=2 D$ to $4 D$ and almost $1 / 2$ when $S=5 D$ to $8 D$.

It is demonstrated that the optimum value of the relative depth of truncation, $C_{\text {opt }}$ varies with the pile diameter and spacing. It is bigger when piles are more flexible and pile spacing is larger as portrayed in Figure 10. For the actual ratio $C$ is below $C_{\text {opt }}$, the value of the FS of piled slope hardly changes with pile truncation, indicating that truncation in this range has no influence on the reinforcement function of piles. Conversely, once the actual ratio $C$ is above $C_{\text {opt }}$, FS decreases rapidly. Truncation in this range will have a serious influence on piled slope stability and the reinforcement function of piles will be much weakened. In practical engineering, piles could be truncated appropriately on the premise of ensuring the reinforcement function; thus resources could be saved and costs could be reduced. It is advised that boreholes could be filled with surrounding soil and compacted in the standard procedure for truncated parts of piles.
4.2. Truncated Stabilizing Pile Behaviors. The bending moment $M$ and shear force $Q$ of truncated stabilizing piles with different pile spacing $S$ and relative depths of truncation, $C$, are shown in Figure 11, and it is noted that the positive direction shear force is identical to the $x$-direction. In this section, the truncated stabilizing piles with $D=0.8 \mathrm{~m}$ for Model A slopes are mainly discussed. The results for $D=1.6$ and $0.4 \mathrm{~m}$ are not presented because they are consistent with those for $D=0.8 \mathrm{~m}$.

It can be seen from Figure 11 that lateral shear force $Q$ along $x$-direction in the pile reaches the first extreme point at a critical depth. This critical depth could be regarded as a level of the potential slip surface because the shear strength reduction method cannot predict a clear slip surface like the limit equilibrium method. Thus depth of potential slip surfaces at the position of piles is shown in Table 3. It can be seen that smaller spacing of piles gives deeper levels of potential slip surface when $C$ is below 0.35 . However, for $C$ above 0.35 , the depth of potential slip surface remains constant regardless of pile spacing. For the same pile spacing, the depth of potential slip surface remains constant when $C$ is below 0.35 and then becomes shallower with $C$ increasing, indicating that overhead sliding may occur.

The values of the first extreme point of shear force $Q_{\max }$ and the maximum bending moment occurring below the slip surface $M_{\max }$ in piles for various pile spacings are discussed. It can be seen from Figure 12(a), when $S=2 D$, that $Q_{\max }$ at potential slip surface remains unchangeable as the value of $C$ is below 0.18 , then decreases slightly as $C$ increases from 0.18 to 0.35 , and finally decreases rapidly with $C$ above 0.35 . For $S=3 D$ to $5 D, Q_{\max }$ at potential slip surface increases slightly as $C$ increases from 0 to 0.35 and then decreases rapidly with $C$ above 0.35 . For $S=6 D$ to $8 D, Q_{\max }$ at potential slip surface increases slightly from $C=0$ to 0.35 , then decreases slowly as $C$ increases from 0.35 to 0.53 , and finally decreases rapidly with $C$ above 0.53 . Shear force in piles at the potential slip surface is generally identical to the resisting reaction force to the sliding mass. Therefore, a larger shear force in piles at 


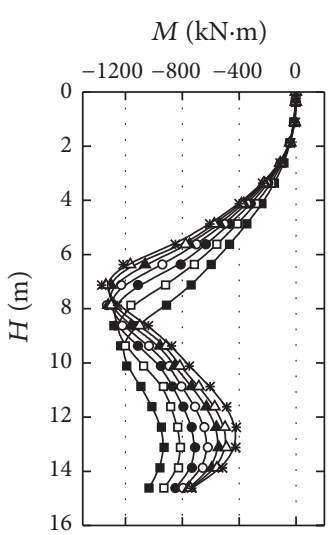

16

$$
\begin{array}{ll}
\rightarrow S=8 D & \rightarrow S=4 D \\
\neg-S=7 D & \rightarrow-S=3 D \\
\neg S=6 D & \rightarrow-S=2 D \\
\multimap-S=5 D &
\end{array}
$$

(a) $C=0$

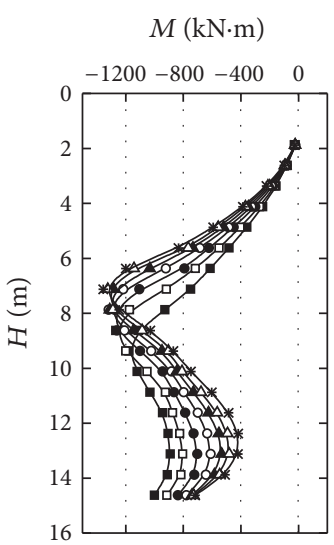

$$
\begin{array}{ll}
\rightarrow S=8 D & \rightarrow S=4 D \\
-\triangle S=7 D & \rightarrow-S=3 D \\
-S=6 D & \rightarrow S=2 D \\
\multimap-S=5 D &
\end{array}
$$

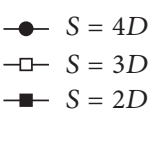

(c) $C=0.35$

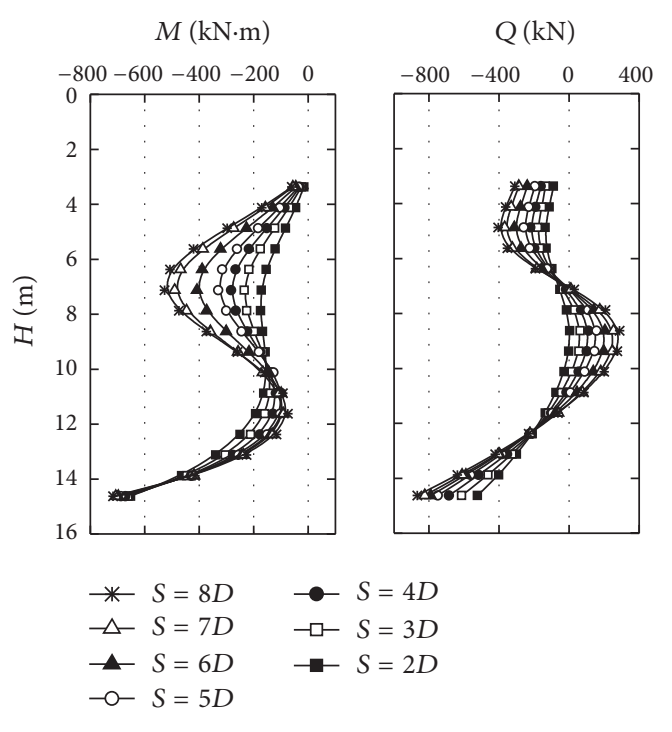

(e) $C=0.71$

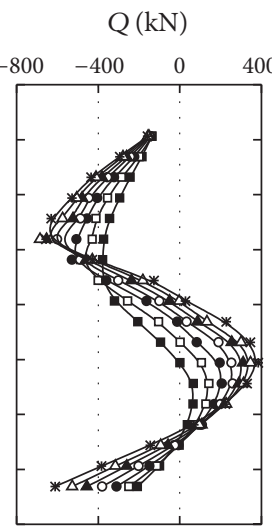

$\mathrm{Q}(\mathrm{kN})$

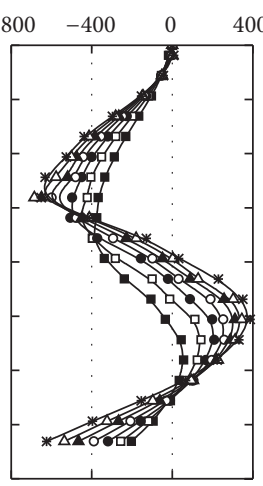

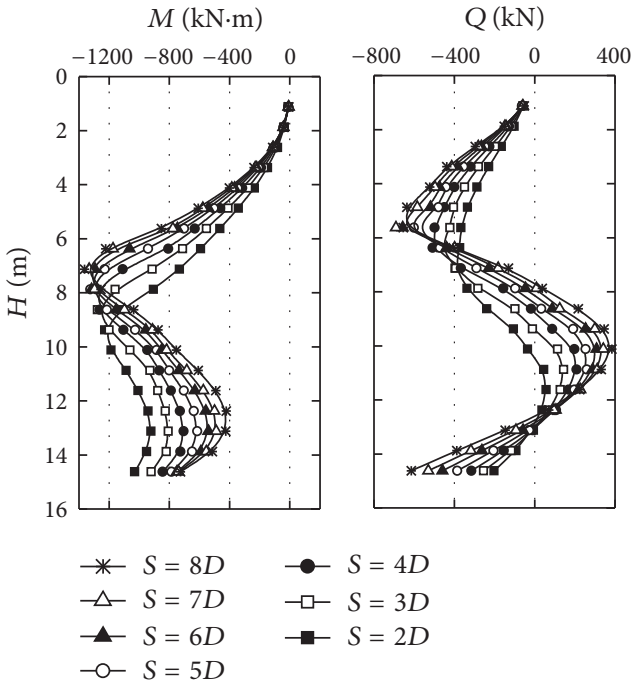

(b) $C=0.18$

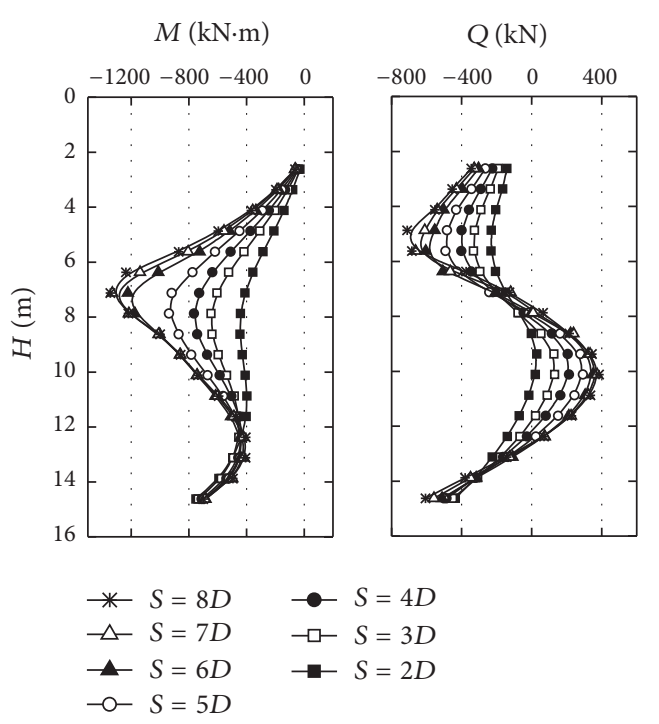

(d) $C=0.53$

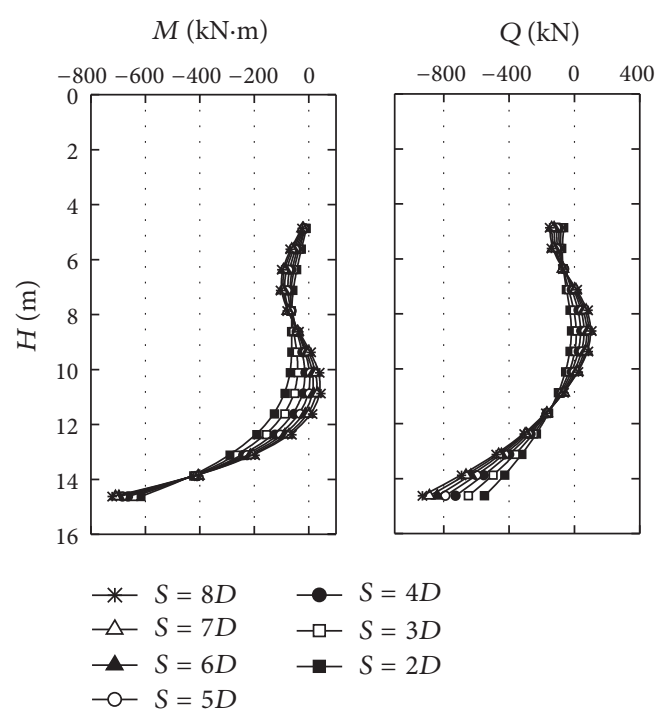

(f) $C=0.88$

FIgURE 11: Truncated pile behavior characteristics for various pile spacing. 
TABLE 3: Depth of a potential slip surface at piles (units: m).

\begin{tabular}{lcccccc}
\hline Relative depth of truncation & \multicolumn{3}{c}{ Pile spacing } \\
& $S=2 D$ & $S=3 D$ & $S=4 D$ & $S=5 D$ & $S=6 D$ & $S=7 D$ \\
\hline$C=0$ & 7.13 & 6.38 & 6.38 & 5.63 & 5.63 & 5.63 \\
$C=0.18$ & 7.13 & 6.38 & 6.38 & 5.63 & 5.63 & 5.63 \\
$C=0.35$ & 7.13 & 6.38 & 6.38 & 5.63 & 5.63 & 5.63 \\
$C=0.53$ & 5.63 & 5.63 & 5.63 & 5.63 & 5.63 & 5.63 \\
$C=0.71$ & 4.88 & 4.88 & 4.88 & 4.88 & 4.88 & 4.63 \\
$C=0.88$ & 4.88 & 4.88 & 4.88 & 4.88 & 4.88 & 4.88 \\
\hline
\end{tabular}

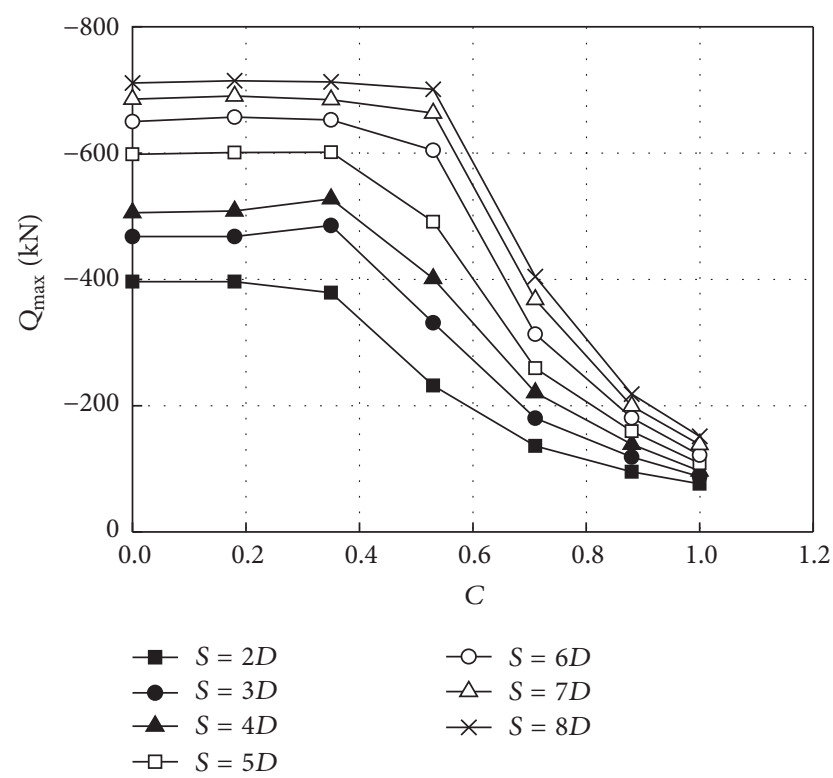

(a) $Q_{\max }$ in piles for different pile spacing and truncating length

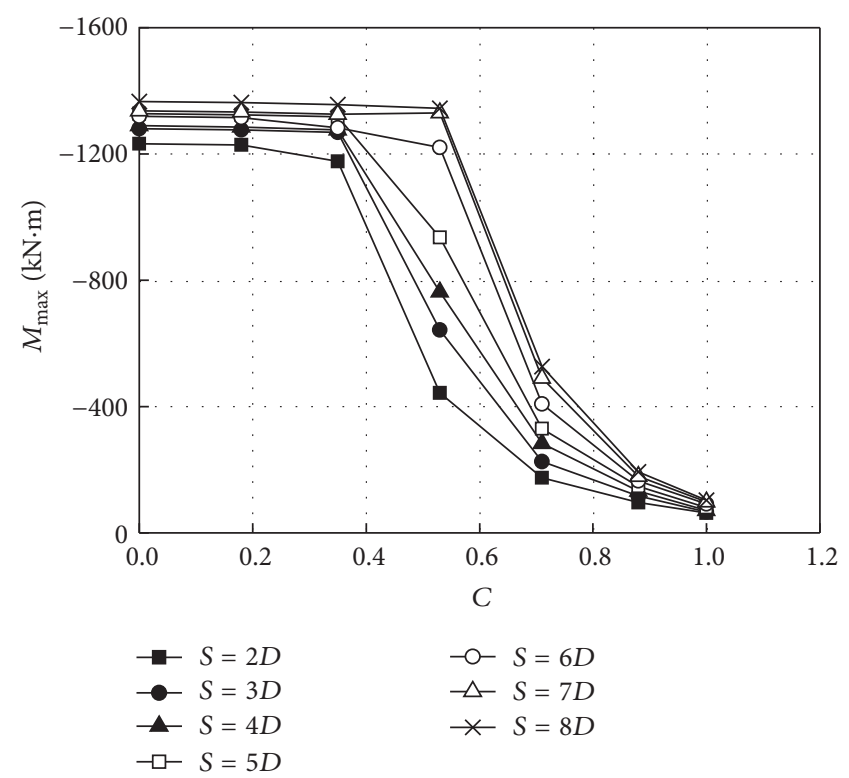

(b) $M_{\max }$ in piles for different pile spacing and truncating length

FIGURE 12: Variation of $Q_{\max }$ and $M_{\max }$ in truncated piles with pile spacing.

potential slip surface corresponds to a larger reaction force to the sliding mass by piles and accordingly will cause a higher factor of safety of the reinforced slope. These results reveal the differences in the FS values of slopes reinforced with different truncated piles.

It can also be seen from Figure 12(b) that maximum bending moment $M_{\max }$ occurs below potential slip surface of piles. For $S=2 D$ to $5 D, M_{\max }$ decreases slightly as $C$ increases from 0 to 0.35 . For $S=6 D$ to $8 D, M_{\max }$ decreases slightly or moderately as $C$ increases from 0 to 0.53 . These results demonstrate that truncation of a pile facilitates the achievement of the rational stress of a pile to a certain extent. These benefits will be particularly important for piled slopes, because piles are more likely to yield by the bending moment rather than by shear force in practical engineering.

4.3. Failure Process of Piled Slope due to Truncation. Failure mode of slopes stabilized with truncated piles $(S=2 D, D=$ $0.8 \mathrm{~m}$ ) is shown in Figures 13-19. When $C$ is below 0.18, it can be seen from Figures 13 and 14 that potential slip surfaces are clearly divided into two parts because of the presence of piles. With $C$ increasing from 0.18 to 0.35 , the potential slip surface in Figure 15 is still two parts at the section near the pile but becomes connected at the section through soil midway between piles. The explanation is that lateral soil movement between piles is less resisted at $C=0.35$, and accordingly, the FS of reinforced slope decreases. When $C$ increases from 0.35 to 0.53 , it can be seen from Figure 16 that potential slip surface at the section through soil midway becomes deeper and shear strain mobilizes along the vertical direction at the interface between soil and pile. With $C$ increasing from $0.53 \mathrm{~m}$ to 0.71 , potential slip surface in Figure 17 clearly becomes a single potential slip surface at the section near pile, indicating that this part of pile cannot supply a resisting force to the slope, and overhead sliding occurs over pile head. When $C$ continuously increases, potential slip surface of overhead sliding becomes deeper and deeper (see Figure 18). When $C$ is equal to or above 1, it can be seen in Figure 19 that potential slip surface becomes the same as an unreinforced slope. These results systematically reveal the failure process of piled slope due to truncation.

4.4. Effect of a Thin Weak Layer. Model B slope shown in Figure 6(b) includes a thin weak layer that runs in an 


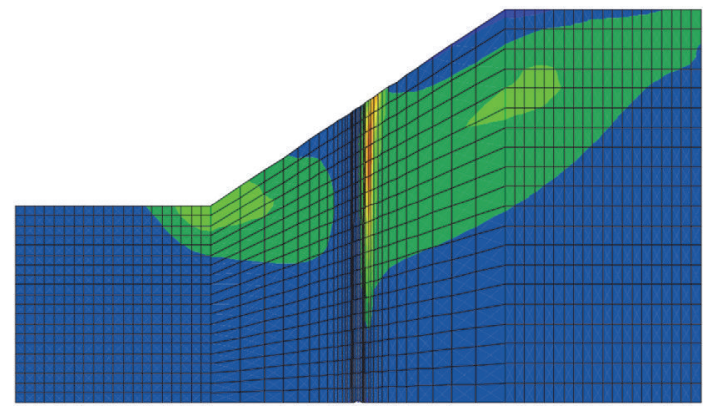

(a) Through pile center line at $y=0$

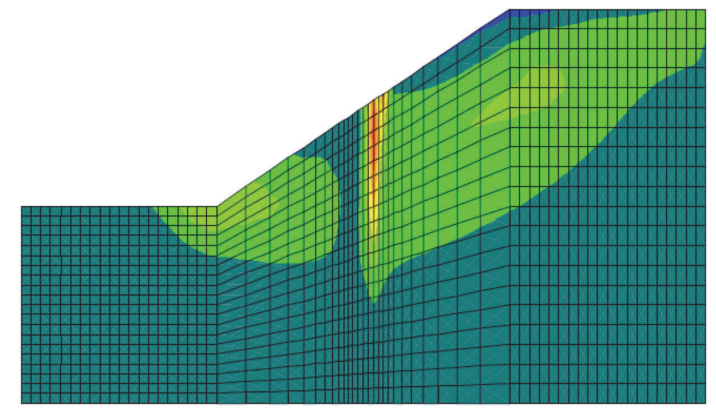

(b) Through soil midway between piles at $y=0.8 \mathrm{~m}$

FIgURE 13: Failure mode of a slope with piles $C=0$ at different sections.

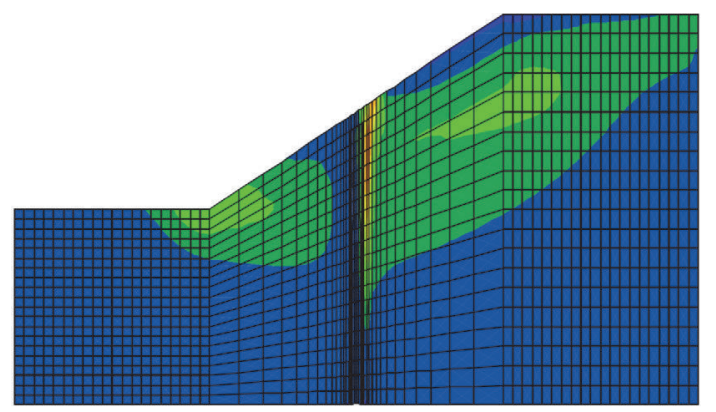

(a) Through pile center line at $y=0$

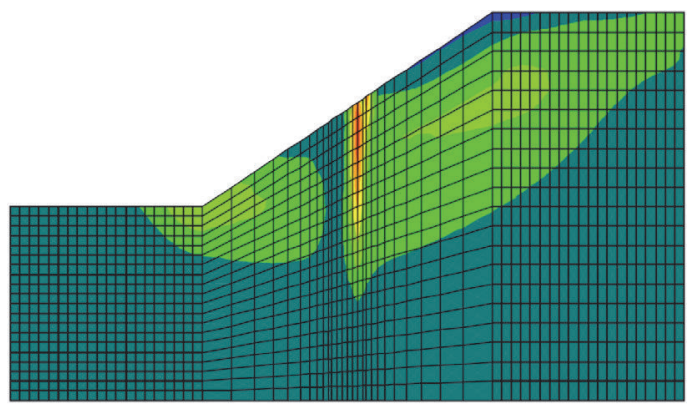

(b) Through soil midway between piles at $y=0.8 \mathrm{~m}$

FIgURE 14: Failure mode of a slope with piles $C=0.18$ at different sections.

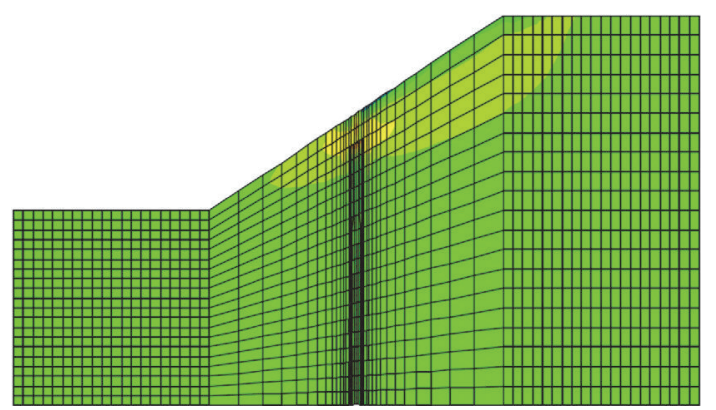

(a) Through pile center line at $y=0$

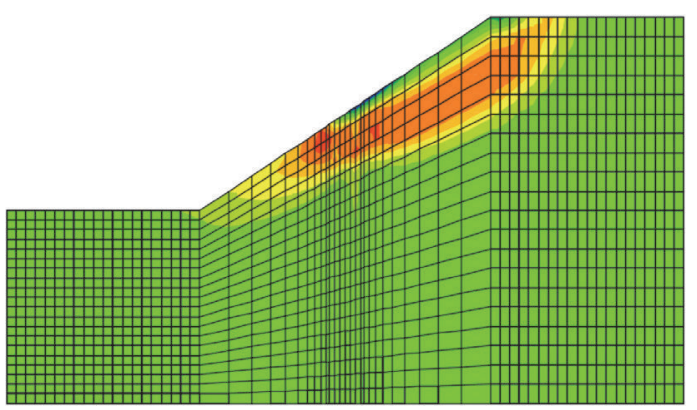

(b) Through soil midway between piles at $y=0.8 \mathrm{~m}$

FIgURE 15: Failure mode of a slope with piles $C=0.35$ at different sections.

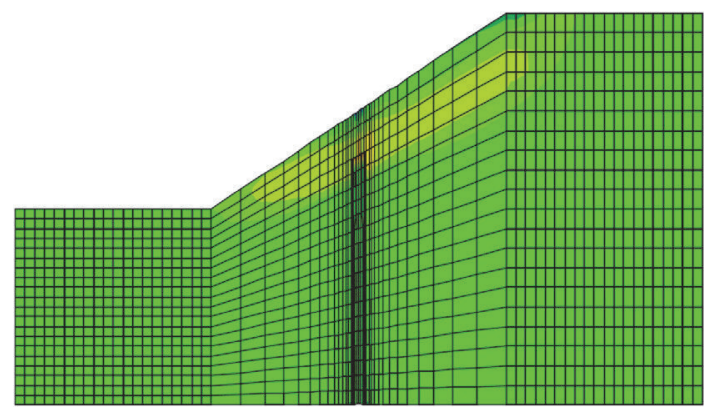

(a) Through pile center line at $y=0$

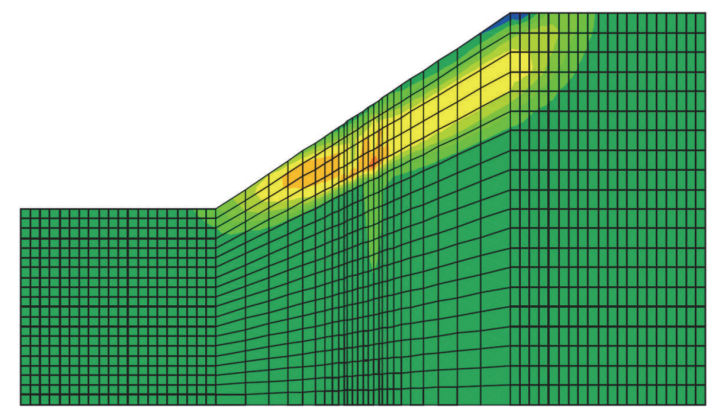

(b) Through soil midway between piles at $y=0.8 \mathrm{~m}$

FIgURE 16: Failure mode of a slope with piles $C=0.53$ at different sections. 


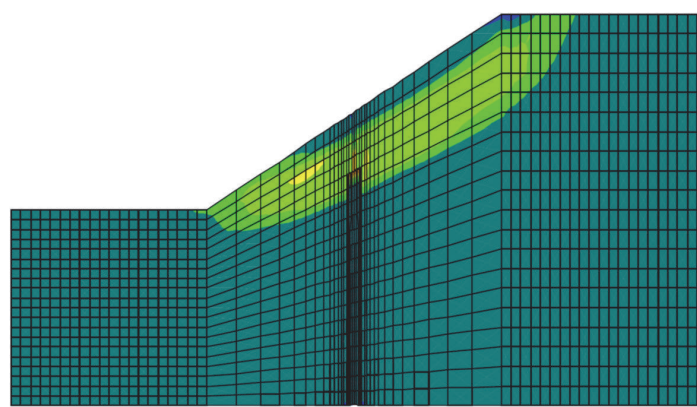

(a) Through pile center line at $y=0$

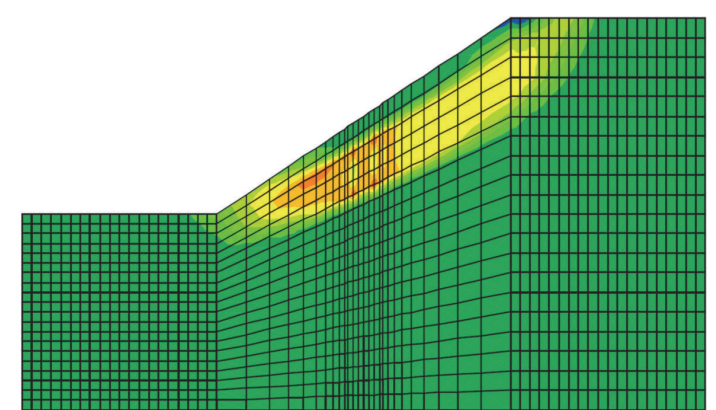

(b) Through soil midway between piles at $y=0.8 \mathrm{~m}$

FIgURE 17: Failure mode of a slope with piles $C=0.71$ at different sections.

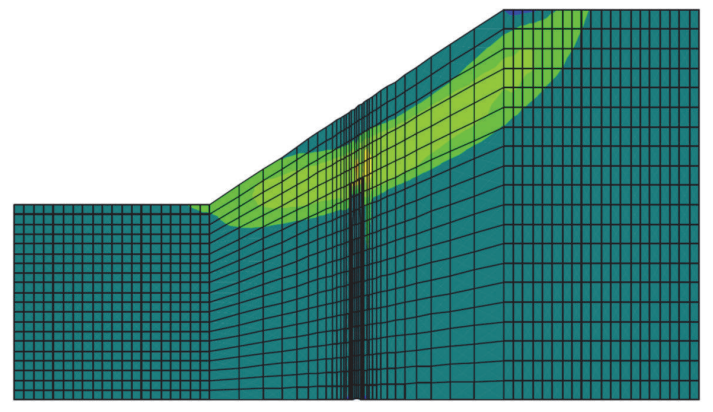

(a) Through pile center line at $y=0$

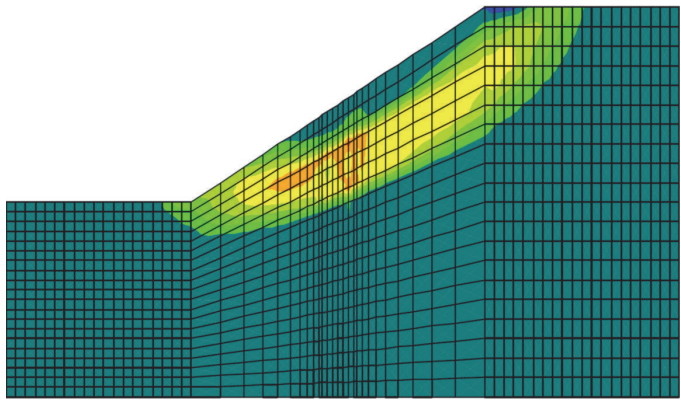

(b) Through soil midway between piles at $y=0.8 \mathrm{~m}$

FIgURE 18: Failure mode of a slope with piles $C=0.88$ at different sections.

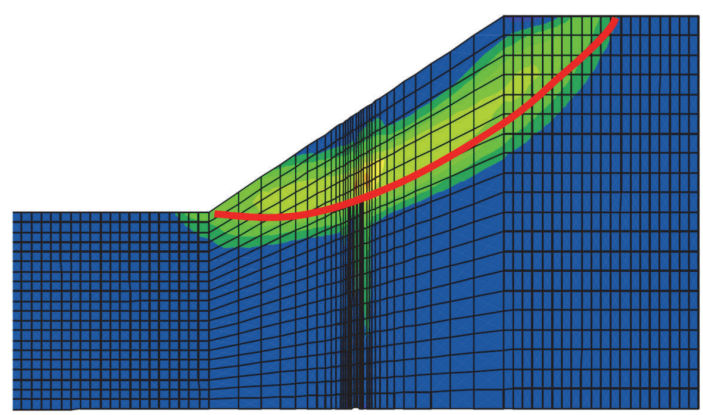

(a) Through pile center line at $y=0$

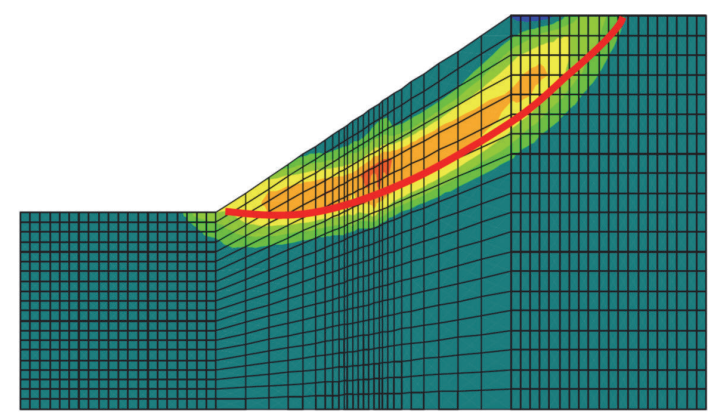

(b) Through soil midway between piles $y=0.8 \mathrm{~m}$

FIGURE 19: Failure mode of a slope with piles $C=1.05$ at different sections (note: the solid line shows the potential slip surface of the unreinforced slope).

approximately circular layer. Here the shape and location of thin weak layer is intentionally designed as the potential slip surface of Model A slope for comparison. It is noted that it is not the typical situation of a thin weak layer within a landfill system. The thickness of layer is $0.1 \mathrm{~m}$, and shear strength parameters of the thin layer $c$ and $\varphi$ are 0.7 times the strength of surrounding soil. Thus, failure of slope may occur along the thin weak layer.

The FS values of Model B slopes stabilized with truncated piles for different pile spacing at $D=0.8 \mathrm{~m}$ are shown in Figure 20; here $C$ is the relative depth of truncation as above. It can be seen that FS decrease as pile spacing increases, as expected, and the FS values of the slopes for Model B are lower than those for model $\mathbf{A}$ at the same truncation depth and pile spacing, indicating that existence of weak layer reduces the stability of reinforced slopes. With $S$ increasing from $2 D$ to $8 D$, it is noted that the rate of decline in FS reduces gradually with $S$ increasing.

It can be seen from Figure 20 that an optimum value of the relative depth of truncation, $C$, exists for piles in Model B slopes. When $S=2 D$, FS of reinforced slope remains unchangeable as $C$ increases from 0 to 0.32 and then decreases rapidly as $C$ increases above 0.32 . While $S=3 D$ to $6 D$, FS of reinforced slope remains unchangeable as $C$ increases from 0 to 0.32 and then decreases slightly as $C$ increases from 0.32 to 0.49 . While $S=7 D$ to $8 D$, FS remains unchangeable as 


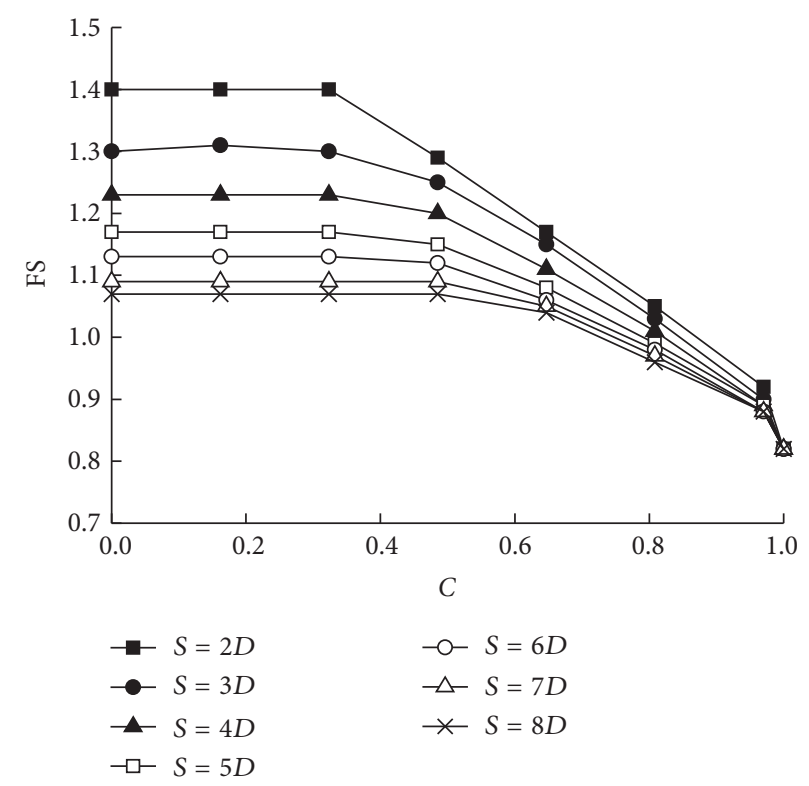

FIgURE 20: FS values of the piled slopes for Model $\mathbf{B}(D=0.8 \mathrm{~m})$.

$C$ increases from 0 to 0.49 and then decreases moderately. When $C$ is equal to or above $1, F S$ is 0.82 , which is the same as an unreinforced slope. The optimal truncation length of pile, beyond which overhead sliding may occur, is investigated with a dimensionless ratio of $C_{\text {opt }}$ as follows:

(1) For $S=2 D$, the value of $C_{\text {opt }}$ can be taken as $1 / 3$.

(2) For $S=3 D$ to $6 D$, the value of $C_{\text {opt }}$ can be taken as between $1 / 3$ and $1 / 2$.

(3) For $S=7 D$ to $8 D$, the value of $C_{\text {opt }}$ can be taken as $1 / 2$.

Comparing $C_{\text {opt }}$ of Model $\mathbf{B}$ piled slopes with that of Model A, it can be seen that the values of $C_{\text {opt }}$ for Model $\mathbf{B}$ are larger than Model $\mathbf{A}$ at the same pile diameter and spacing, indicating that effect of truncation could be more beneficial for piled slopes with a thin weak layer. These benefits will be particularly important in practical engineering because sliding along a preexisting interface has been demonstrated to be typical of many actual observed slope failures.

Failure mode of Model B slopes reinforced with truncated piles at $S=2 D(D=0.8 \mathrm{~m})$ are shown in Figure 21; here sections $y=0$ through pile center line are presented for comparison. It can be seen that failure mode of slopes shows mainly expected circular failure mechanism along a preexisting weak layer. And, when $C$ is below 0.32, from Figures 21(a) and 21(b), it can be seen that the potential slip surface is divided into two parts by the pile. While $C$ reaches 0.65 , the potential slip surface in Figure 21(c) becomes more complex. Two conflicting mechanisms are clearly seen: one is a base mechanism merging with mass above pile head beyond toe of reinforced slope, and the other is a mechanism of sliding along the preexisting weak layer. When $C$ increases to 0.97 , the potential slip surface in Figure 21(d) shows a single surface indicating that overhead sliding occurs. It can be seen from Figure 21(e) that the potential slip surface is the same as the unreinforced slope in Figure 6(b) when $C$ increases to 1.0.

\section{Conclusions}

A novel engineering technique of truncated pile for slope stabilization was introduced in this paper. The truncated piles are more economical and rational than conventional full length piles due to their shortened length and smaller load.

A simplified numerical method was proposed to analyze the stability of slopes stabilized with truncated piles based on the shear strength reduction method, in which the soil behavior is described using the nonassociated MohrCoulomb criterion and a pile is modeled as $3 \mathrm{D}$ continuum elements. The reliability of the proposed method was tested using an example from Cai and Ugai [13]. The value of factor of safety on the nonreinforced slope was equal to 1.17, which was close to Cai and Ugai's results with safety factors of 1.14 for a homogenous slope.

The influential factors including pile diameter, pile spacing, depth of truncation, and existing a weak layer were systematically investigated by the proposed method from a practical point of view. It is found that an optimum ratio exists between depth of truncation and length of pile above critical slip surface. For the actual ratio is below the optimum value, the factor of safety of reinforced slope hardly changes with the pile truncation, indicating that truncation in this range has little influence on the reinforcement function of piles. Conversely, once the actual ratio is above the optimum value, truncation will play a serious influence on reinforced slope stability and the reinforcement function of piles will be much weakened. In practical engineering, piles could be truncated appropriately on the premise of ensuring the reinforcement function; thus resources could be saved and costs could be reduced. It is advised that borehole could be filled with surrounding soil and compacted in the standard procedure for the truncated part of piles.

The authors proposed an index, $C$, to investigate the relative depth of truncation of piles in slope stabilization. It is 


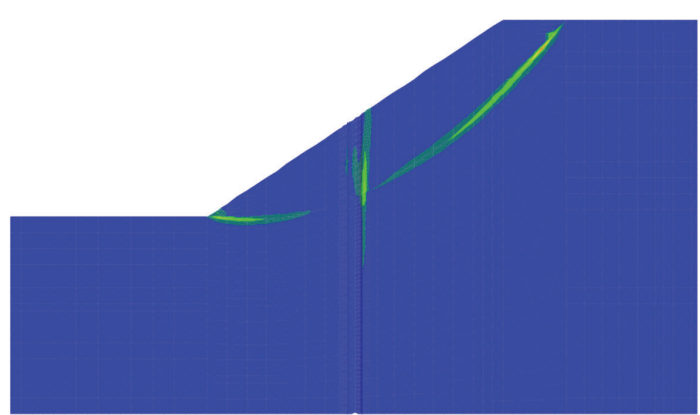

(a) $C=0$

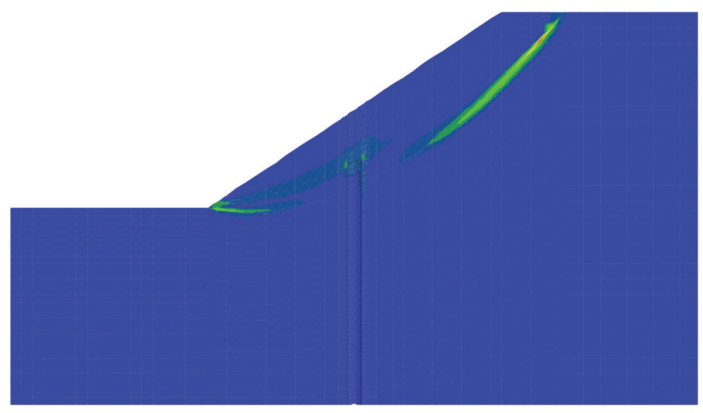

(c) $C=0.65$

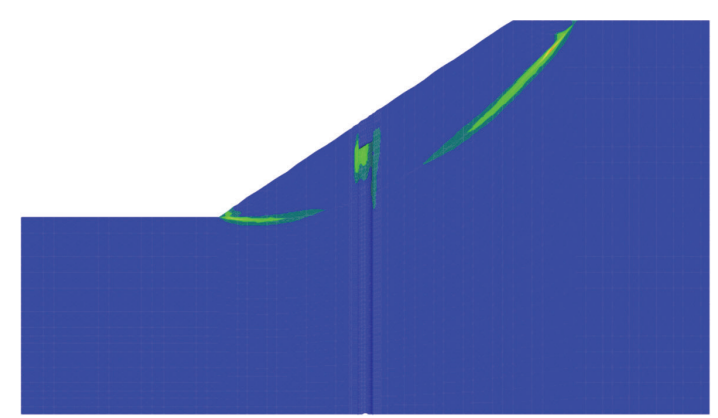

(b) $C=0.32$

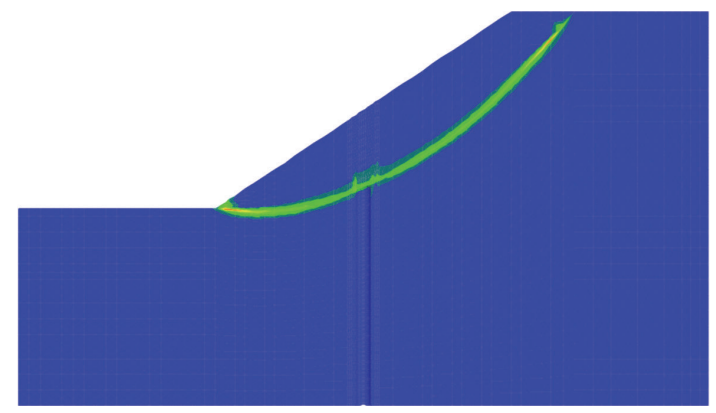

(d) $C=0.97$

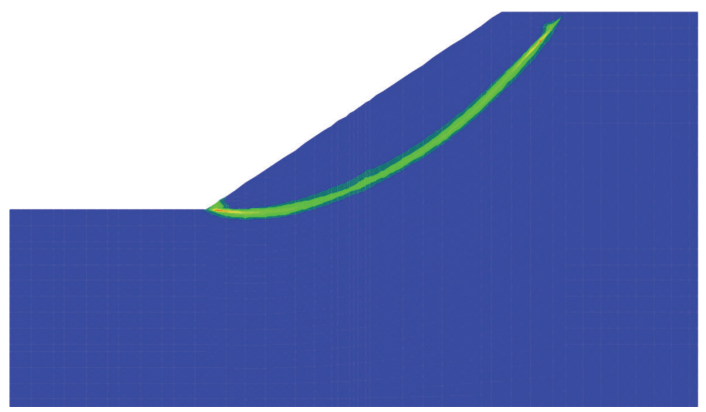

(e) $C=1.0$

FIGURE 21: Failure mode of piled slopes for Model B (at $y=0$ section).

demonstrated that the optimum value of the relative depth of truncation, $C_{\text {opt }}$, varies with pile diameter and spacing, which is larger when piles are more flexible and the pile spacing is larger. It should also be noted that the values of $C_{\text {opt }}$ for slopes with a thin weak layer are larger than homogenous slopes with the same pile diameter and spacing, indicating that effect of truncation could be more beneficial for piled slopes with a preexisting interface. These benefits are particularly important in practical engineering because sliding along a preexisting interface has been demonstrated to be typical of many actual observed slope failures.

The current 3D slope stability analysis is based on a simple homogeneous slope. However, the geometry of real slopes is more complex. For example, a natural slope often has curvature, and irregular surfaces appear in open-pit and roadside design. Besides, soil properties typically exhibit considerable variation from point to point even within nominally homogenous soil layers. Therefore, further research is required to consider the effect of complex geometries and material spatial variability.

\section{Competing Interests}

The authors declare that they have no competing interests.

\section{Acknowledgments}

This work was supported by the Chinese National Science Fund (nos. 51574245 and 41002090) and the State Key Laboratory of Coal Resources and Safe Mining (China University of Mining and Technology) (no. SKLCRSM16KFB05).

\section{References}

[1] R. Merriam, "Portuguese bend landslide, Palos Verdes Hills, California," The Journal of Geology, vol. 68, no. 2, pp. 140-153, 1960. 
[2] E. E. De Beer and M. Wallays, "Stabilization of a slope in schist by means of bore piles reinforced with steel beams," in Proceedings of the 2nd International Conference on Rock Mechanics, vol. 3, pp. 361-369, Belgrade, Serbia, 1970.

[3] T. Ito and T. Matsui, "Methods to estimate lateral force acting on stabilizing piles," Soils and Foundations, vol. 15, no. 4, pp. 43-59, 1975.

[4] C. Viggiani, "Ultimate lateral load on piles used to stabilize landslide," in Proceedings of the 10th International Conference on Soil Mechanics and Foundation Engineering, vol. 3, pp. 555-560, Balkema, Rotterdam, The Netherlands, 1981.

[5] H. G. Poulos, "Design of reinforcing piles to increase slope stability," Canadian Geotechnical Journal, vol. 32, no. 5, pp. 808818, 1995.

[6] J. A. Smethurst and W. Powrie, "Monitoring and analysis of the bending behaviour of discrete piles used to stabilise a railway embankment," Geotechnique, vol. 57, no. 8, pp. 663-677, 2007.

[7] R. Y. Liang, A. E. Joorabchi, and L. Li, "Analysis and design method for slope stabilization using a row of drilled shafts," Journal of Geotechnical and Geoenvironmental Engineering, vol. 140, no. 5, Article ID 04014001, pp. 1-12, 2014.

[8] H. Seo, D. Basu, M. Prezzi, and R. Salgado, "Load-settlement response of rectangular and circular piles in multilayered soil," Journal of Geotechnical and Geoenvironmental Engineering, vol. 135, no. 3, pp. 420-430, 2009.

[9] T. Ito, T. Matsui, and W. P. Hong, "Design method for stabilizing piles against landslide-one row of piles," Soils and Foundations, vol. 21, no. 1, pp. 21-37, 1981.

[10] T. Ito, T. Matsui, and W. P. Hong, "Extended design method for multi-row stabilizing piles against landslide," Soils and Foundations, vol. 22, no. 1, pp. 1-13, 1982.

[11] T. Yamagami, J. C. Jiang, and K. Ueno, "A limit equilibrium stability analysis of slopes with stabilizing piles," in Proceeding of the Sessions of Geo-Denver, pp. 343-354, Denver, Colo, USA, 2000.

[12] Y. K. Chow, "Analysis of piles used for slope stabilization," International Journal for Numerical and Analytical Methods in Geomechanics, vol. 20, no. 9, pp. 635-646, 1996.

[13] F. Cai and K. Ugai, "Numerical analysis of the stability of a slope reinforced with piles," Soils and Foundations, vol. 40, no. 1, pp. 73-84, 2000.

[14] W. B. Wei and Y. M. Cheng, "Strength reduction analysis for slope reinforced with one row of piles," Computers and Geotechnics, vol. 36, no. 7, pp. 1176-1185, 2009.

[15] D. J. White, H. Yang, M. Thompson, and V. R. Schaefer, "Innovative solution for slope stability reinforcement and characterization: vol 1," CREC Project 03-127, Institute for Transportation, Ames, Iowa, USA, 2005.

[16] S.-W. Sun, F.-Q. Chen, and W. Wang, "Mechanism and remediation of a seismically induced landslide with a potential for deep seated sliding," Soil Mechanics and Foundation Engineering, vol. 52, no. 3, pp. 155-162, 2015.

[17] S.-W. Sun, W. Wang, and F. Zhao, "Three-dimensional stability analysis of a homogeneous slope reinforced with micropiles," Mathematical Problems in Engineering, vol. 2014, Article ID 864017, 11 pages, 2014.

[18] E. M. Comodromos and K. D. Pitilakis, "Response evaluation for horizontally loaded fixed-head pile groups using 3-D nonlinear analysis," International Journal for Numerical and Analytical Methods in Geomechanics, vol. 29, no. 6, pp. 597-625, 2005.
[19] E. M. Comodromos and M. C. Papadopoulou, "Response evaluation of horizontally loaded pile groups in clayey soils," Geotechnique, vol. 62, no. 4, pp. 329-339, 2012.

[20] O. C. Zienkiewicz, C. Humpheson, and R. W. Lewis, "Associated and nonassociated viso-plasticity and plasticity in soil mechanics," Geotechnique, vol. 25, no. 4, pp. 671-689, 1975.

[21] D. V. Griffiths and P. A. Lane, "Slope stability analysis by finite elements," Geotechnique, vol. 49, no. 3, pp. 387-403, 1999.

[22] Itasca Consulting Group, FLAC3D 5.0 Manual, Itasca Consulting Group, Minneapolis, Minn, USA, 2012.

[23] D. V. Griffiths and R. M. Marquez, "Three-dimensional slope stability analysis by elasto-plastic finite elements," Geotechnique, vol. 57, no. 6, pp. 537-546, 2007. 

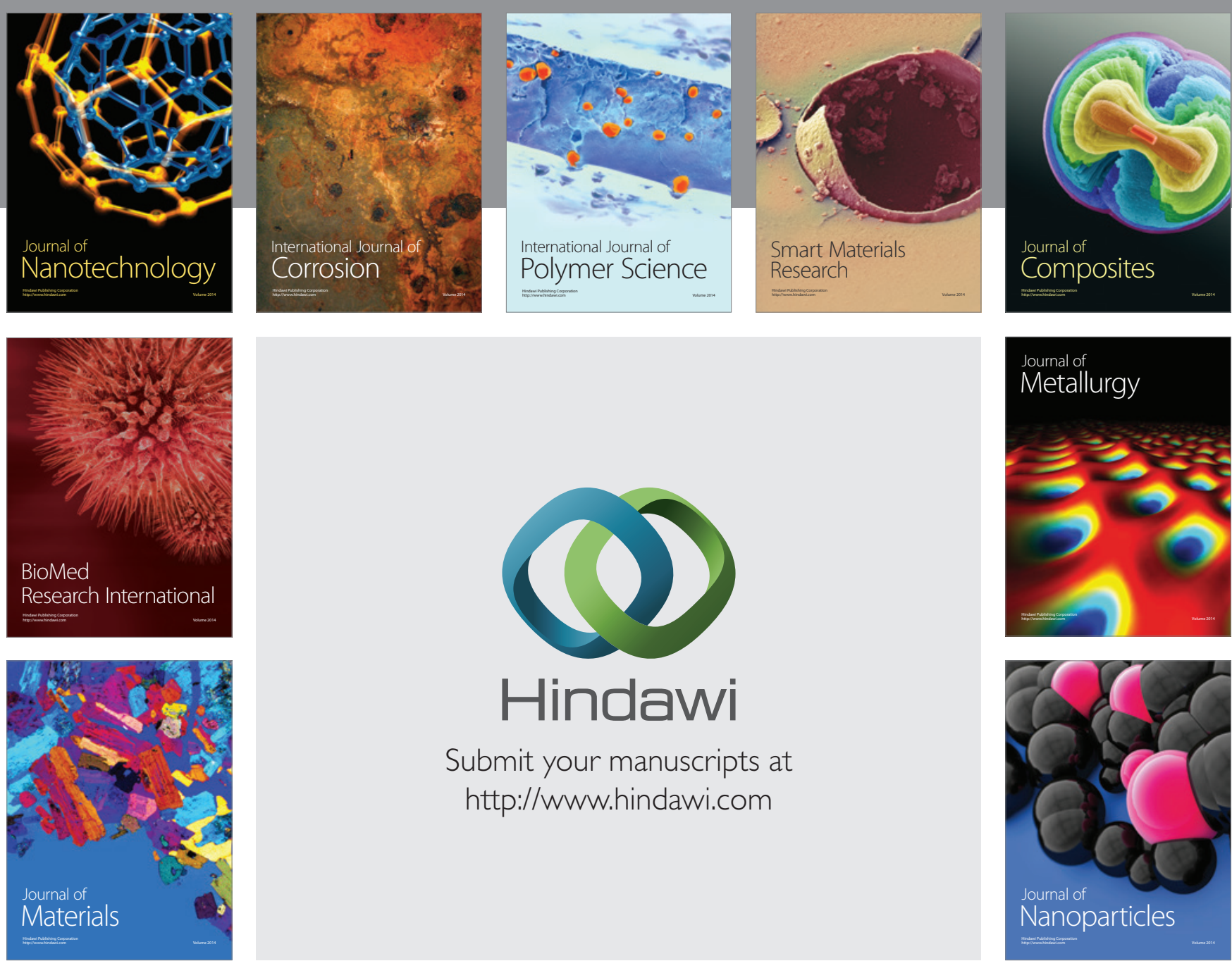

\section{Hindawi}

Submit your manuscripts at

http://www.hindawi.com

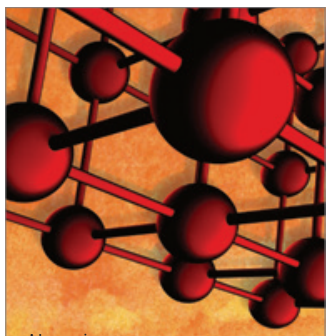

Materials Science and Engineering
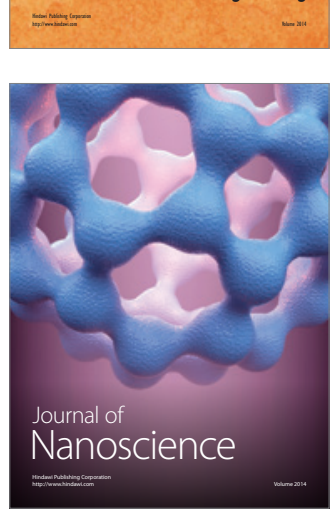
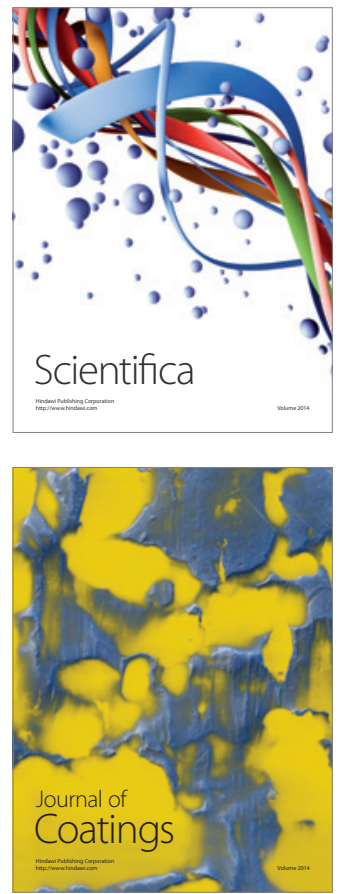
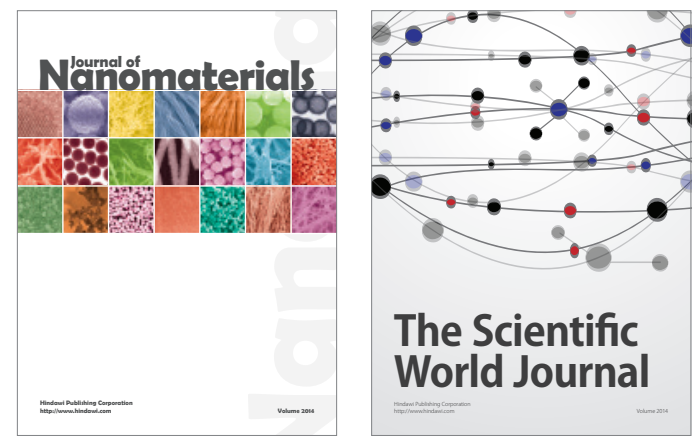

The Scientific World Journal
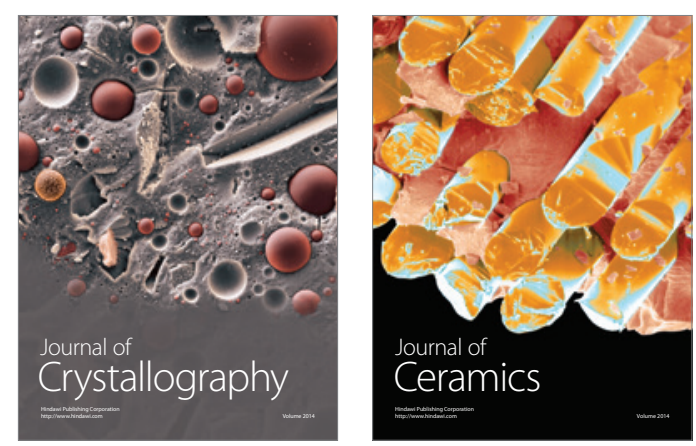
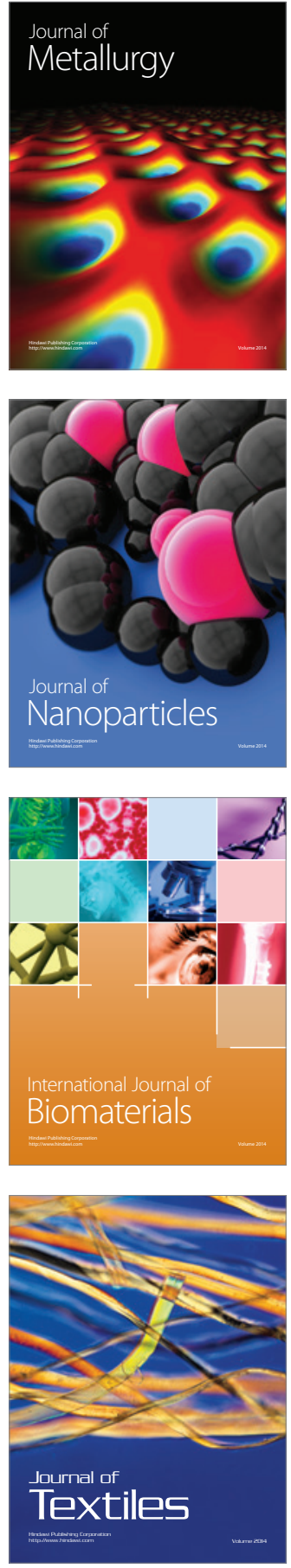